\title{
Transposable element-assisted evolution and adaptation to host plant within the Leptosphaeria maculans-Leptosphaeria biglobosa species complex of fungal pathogens
}

\author{
Jonathan Grandaubert ${ }^{1}$, Rohan GT Lowe ${ }^{2}$, Jessica L Soyer ${ }^{1}$, Conrad L Schoch ${ }^{3}$, Angela P Van de Wouw², \\ Isabelle Fudal ${ }^{1}$, Barbara Robbertse ${ }^{3}$, Nicolas Lapalu4 ${ }^{4}$, Matthew G Links5 5 , , Bénédicte Ollivier ${ }^{1}$, Juliette Linglin ${ }^{1}$, \\ Valérie Barbe ${ }^{7}$, Sophie Mangenot ${ }^{7}$, Corinne Cruaud ${ }^{7}$, Hossein Borhann ${ }^{5}$, Barbara J Howlett ${ }^{2}$, \\ Marie-Hélène Balesdent ${ }^{1}$ and Thierry Rouxel ${ }^{1 *}$
}

\begin{abstract}
Background: Many plant-pathogenic fungi have a tendency towards genome size expansion, mostly driven by increasing content of transposable elements (TEs). Through comparative and evolutionary genomics, five members of the Leptosphaeria maculans-Leptosphaeria biglobosa species complex (class Dothideomycetes, order Pleosporales), having different host ranges and pathogenic abilities towards cruciferous plants, were studied to infer the role of TEs on genome shaping, speciation, and on the rise of better adapted pathogens.

Results: L. maculans 'brassicae', the most damaging species on oilseed rape, is the only member of the species complex to have a TE-invaded genome (32.5\%) compared to the other members genomes (<4\%). These TEs had an impact at the structural level by creating large TE-rich regions and are suspected to have been instrumental in chromosomal rearrangements possibly leading to speciation. TEs, associated with species-specific genes involved in disease process, also possibly had an incidence on evolution of pathogenicity by promoting translocations of effector genes to highly dynamic regions and thus tuning the regulation of effector gene expression in planta.

Conclusions: Invasion of L. maculans 'brassicae' genome by TEs followed by bursts of TE activity allowed this species to evolve and to better adapt to its host, making this genome species a peculiarity within its own species complex as well as in the Pleosporales lineage.
\end{abstract}

Keywords: Comparative genomics, Fungal plant pathogen, Transposable elements, Effector genes, Speciation, Adaptation to host

\section{Background}

Fungi (and fungal-like oomycetes) are an incredibly diverse and adaptable group of organisms which colonise all habitats on Earth. Some are plant and animal pathogens of major economic importance and as stressed by Kupferschmidt [1], "Fungi have now become a greater global threat to crops, forests, and wild animals than ever before. They have killed countless amphibians, pushing

\footnotetext{
* Correspondence: rouxel@versailles.inra.fr

'INRA-Bioger, UR1290, Avenue Lucien Brétignières, BP 01, 78850 Thiverval-Grignon, France

Full list of author information is available at the end of the article
}

some species to extinction, and they are threatening the food supply for billions of people." The sequencing of fungal genomes (the yeast Saccharomyces cerevisiae [2], followed by filamentous ascomycetes such as Neurospora crassa [3], and later plant pathogenic fungi such as Ustilago maydis, Magnaporthe oryzae, Fusarium graminearum and Phaeosphaeria nodorum [4-7]) initially indicated that genomes of filamentous ascomycetes are relatively small (21-39 Mb), with few repetitive elements (typically less than 10\%) and they contain 10,000-15,000 protein-encoding genes. Unlike symbiotic and parasitic bacteria, which usually have smaller genomes than 
their free-living relatives [8], the first genome data from filamentous fungi did not indicate differences between genome size of fungal pathogens and that of saprophytes. However, contrasting to what is observed in bacteria, recent sequence data indicate that some phytopathogens have drastically expanded genomes, mostly due to massive invasion by Transposable Elements (TEs).

The 45-Mb genome of Leptosphaeria maculans, the ascomycete that causes stem canker of crucifers contains $33 \% \mathrm{TEs}$, the $120-\mathrm{Mb}$ genome of cereal downy mildew, Blumeria graminis, contains $64 \%$ TEs (while other closely related downy mildew pathogens have even larger genomes), and that of the 240-Mb oomycete Phytophthora infestans contains $74 \%$ TEs [8]. These data, suggesting convergent evolution towards bigger genomes in widely divergent fungal and oomycete species, are intriguing and the counterbalance between selective advantage conferred to the pathogen and the cost of maintaining this amount of "parasitic" DNA is unknown.

Analysis of L. maculans 'brassicae' (Lmb) genome [9] revealed a genomic structure at this time only observed in mammals and other vertebrates: the base composition (GC-content) varied widely along the chromosomes, but locally, was relatively homogeneous. Such structural features of chromosomes are termed "isochores" [10]. In $\mathrm{Lmb}$, the high TE proportion in conjunction with RIP (Repeat-Induced Point mutation) [11] generates large AT-rich regions (33.9\% GC-content), called AT-isochores. These AT-isochores are scattered along the genome alternating with large GC-equilibrated regions (51\% GC-content), GC-isochores, containing $95 \%$ of the predicted genes and mostly devoid of TEs. AT-isochores cover $36 \%$ of L. maculans genome, are mainly composed of mosaics of truncated and RIP-degenerated TEs and only contain 5\% of the predicted genes, but $20 \%$ of those genes encode small secreted proteins (SSPs) considered as putative effectors of pathogenicity [9]. As only $4 \%$ of the genes located in GC-isochores encode SSPs, we hypothesized that ATisochores were niches for putative effectors. This was corroborated by the presence within these AT-isochores of genes encoding known effectors, including four avirulence genes (i.e. encoding proteins recognised by plant resistance genes), AvrLm1 [12], AvrLm6 [13], AvrLm4-7 [14] and AvrLm11 [15]. Moreover, genes within AT-isochores are affected by RIP, which can occasionally overrun the repeated region into adjacent single-copy genes, resulting in extensive mutation of the affected genes [16-18]. This genome environment favors a rapid response to selection pressure. For example, effector genes acting as avirulence genes can be inactivated in a single sexual cycle due to RIP or deletions due to large-scale genome rearrangements in AT-isochores $[16,18,19]$.

In addition to genes encoding effectors and genes with no predicted function, AT-isochores are also enriched in gene clusters responsible for the biosynthesis of secondary metabolites [9]. Both effector genes and secondary metabolite gene clusters are distributed discontinuously among ascomycetes and/or show species specificity $[9,20]$. We have postulated that genome invasion by TEs, followed by their degeneracy by RIP shaping large AT-isochores, is a recent evolutionary event that has contributed to the rise of a better adapted new species, and that maintaining large TE-rich regions hosting pathogenicity determinants has favoured adaptation to new host plants along with generation of new virulence specificities [9].

This hypothesis can be now tested by exploiting comparative genomics between Lmb and other members of the Leptosphaeria species complex, for which preliminary electrokaryotype and Southern blot analyses suggested only limited TE content (Additional file 1: Figure S1). $L$. maculans and L. biglobosa are dothideomycete phytopathogens specialized on crucifers and encompassing a series of ill-defined entities more or less adapted to oilseed rape/ canola (Brassica napus). Some of the species of the complex attack oilseed rape and are responsible for the main disease of the crop (blackleg or Phoma stem canker) [21-23]. The complex also encompasses related lineages only found on cruciferous weeds. These include $L$. maculans 'lepidii' (Lml) isolated from Lepidium spp. and L. biglobosa 'thlaspii' (Lbt) isolated from Thlaspi arvense, but also found occasionally on Brassica species in Canada [21,22]. The L. maculans and L. biglobosa lineages infecting B. napus (Lmb, L. biglobosa 'brassicae' (Lbb) and L. biglobosa 'canadensis' (Lbc)) share morphological traits, epidemiology, initial infection strategies, ecological niches and regardless of geographic distribution, are often found together in tissues of individual infected plants [24].

In this paper we investigate when and how genome expansion took place in the L. maculans-L. biglobosa species complex, and the consequences it had on genome structure, adaptability and pathogenicity. The genomes of five members of the species complex ( $\mathrm{Lml}, \mathrm{Lbb}, \mathrm{Lbc}$, Lbt and another isolate of Lmb) were sequenced. The genomic data were analysed and compared to those from other dothideomycete species to address the following questions: (i) Do the different members of the species complex constitute separate biological species and did TEs contribute to speciation? (ii) Did TE invasion contribute to the rise of a better adapted and more adaptable species: i.e. what was the incidence of TE invasion on the generation, modification, loss or regulation of pathogenicity determinants?

\section{Results}

Phylogeny and estimates of divergence times

L. maculans and L. biglobosa belong to order Pleosporales from the class Dothideomycetes. This class is the largest 
and the most phylogenetically diverse within Pezizomycotina (filamentous ascomycetes), and includes numerous plant pathogens such as species in the genera Cochliobolus, Phaeosphaeria, Pyrenophora, Mycosphaerella, Zymoseptoria and Venturia [25,26] (Figure 1).

The chronogram presented in Figure 1 (for a more detailed analysis see Additional file 2: Figure S2), based on the alignment of 19 conserved proteins, has representatives from three of the four main classes in the Pezizomycotina, but the main focus is on Dothideomycetes. This phylogeny is congruent with other more complete analyses [25,27] and indicates that the Leptosphaeria species diverged from the sampled plant pathogens of Pleosporaceae (Cochliobolus, Pyrenophora and Alternaria) approximately 73 MYA.

Based on morphological features, L. maculans and $L$. biglobosa were considered as two pathotypes of the same species for more than 70 years $[28,29]$ until formal renaming in 2001 [30]. Our data estimate that $L$. maculans and L. biglobosa diverged ca. 22 MYA (Figure 1).

Divergence times were also determined within the $L$. maculans and L. biglobosa lineages. Voigt et al. [22] suggested that Lbt was distinct from the other L. biglobosa sub-clades, which is supported by our current data since it diverged ca. 11 MYA from the terminal Lbb or Lbc (Figure 1). In terminal branches, divergence time between Lmb and Lml (5.1 MYA) and that of Lbb and Lbc (3.6 MYA) are comparable (Figure 1).

\section{Genome statistics}

The reference genome of Lmb (of isolate v23.1.3), was sequenced in 2007 using a whole genome shotgun strategy and Sanger technology [9]. Here, Next Generation Sequencing (NGS) technologies were used to sequence

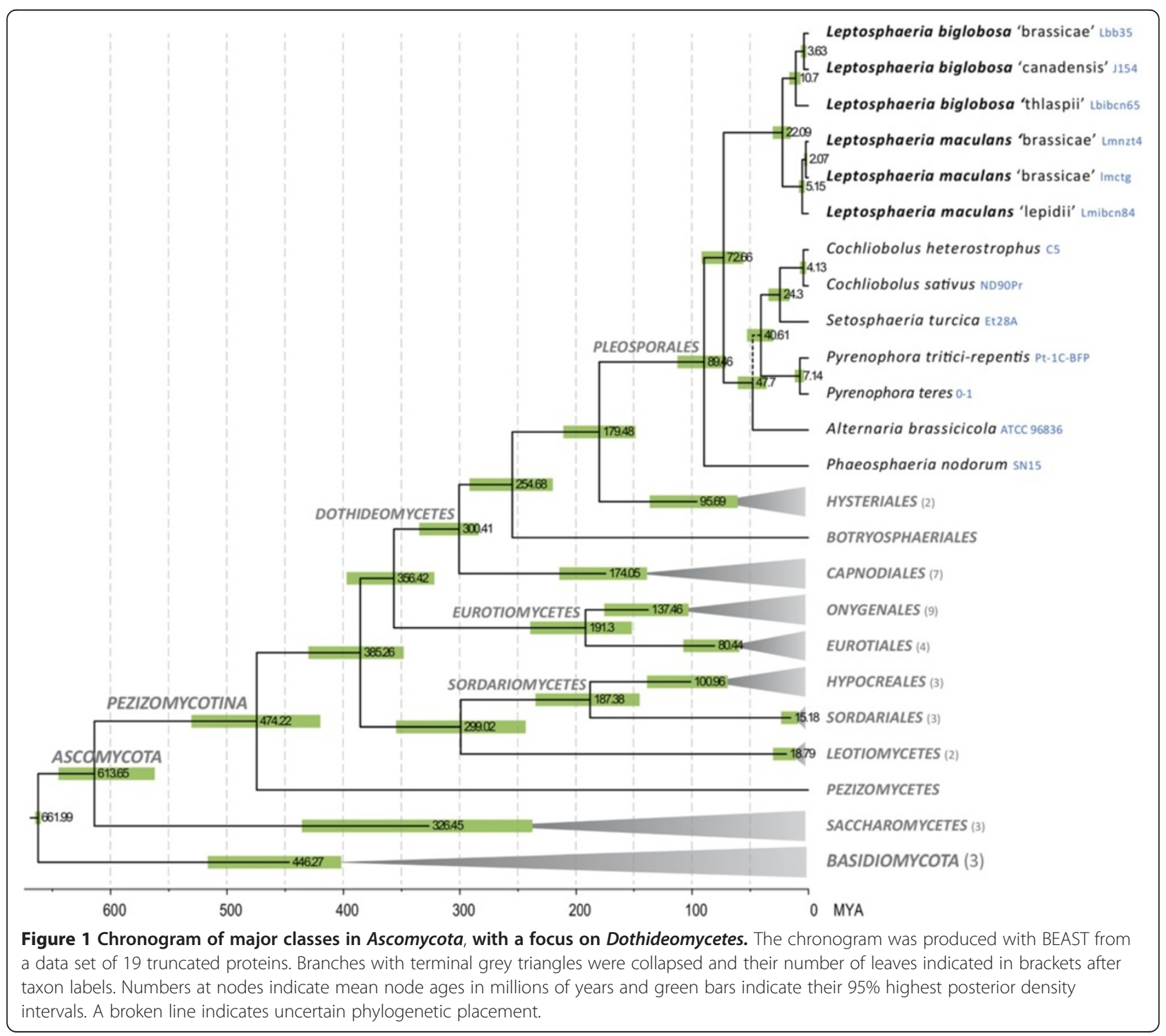


the genomes of five members of the species complex, including another isolate of Lmb. Despite different sequencing and assembly strategies, the resequenced isolate of Lmb (WA74) had a similar genome size and proportion of TEs (25.8\%) compared to v23.1.3 (32.5\% of TEs) (Table 1).

Compared to the Lmb isolates, the other members of the species complex had smaller genomes, ranging from 30.2 to $32.1 \mathrm{Mb}$ and only comprising $2.7 \%$ to $4.0 \%$ of TEs. These sequencing data are consistent with electrokaryotypes done using Pulsed Field Gel Electrophoresis (PFGE) and results of DNA hybridization with known TEs (Additional files 1 and 3: Figures S1, S5).

The GC-content of the Lmb reference genome was $45 \%$, which is similar to that of Lmb isolate WA74 (Table 1). In contrast, all other isolates of the species complex had genome GC-contents ( $c a .51 \%$, Table 1) that related more to those of other Dothideomycetes (50-52\%, Additional file 4: Table S1), with a couple of exceptions discussed below $[26,31,32]$. These data indicate that Lmb is an exception in terms of TE-content compared to other Pleosporales including closely related members of the species complex (Figure 1). Only dothideomycete species of order Capnodiales such as Pseudocercospora fijiensis and Cladosporium fulvum have genomes enriched in TEs, resulting in low overall GC-content of their genome [26,31] (Additional file 4: Table S1).

In the L. maculans-L. biglobosa species complex, the amount of non-repetitive DNA was very similar $c a$. 28$29 \mathrm{Mb}$ (Table 1). This indicates that the size differences between genomes are essentially due to a difference in TE amount and not due to expansion or loss of gene families, as found in other fungi $[33,34]$. Gene annotation predicted a comparable number (10624 to 11691) of proteinencoding genes in all genomes (Table 1). For each genome, the gene features were also very similar in terms of mean gene length, mean coding sequence length or proportion of genes with introns (Additional file 5: Table S2).

\section{Chromosomal organisation and synteny}

Lmb was estimated to have 17-18 chromosomes by combination of analysis of electrokaryotypes developed by PFGE (Additional file 1: Figure S1) and sequencing of the reference genome [9]. The new genomic data described here, especially those of the well-assembled genome of Lml (Table 1; Figure 2) and optical maps of Lmb, allowed this estimate to be refined by considering scaffolding errors on the reference assembly. With the support of genetic mapping, the chromosome count was updated to 19 (Additional file 6: Table S3), including the dispensable chromosome [15] only present in the two $\mathrm{Lmb}$ isolates. As a direct consequence to the overall GC-content of the genomes, the limited amount of TEs in Lml, Lbb, Lbc and Lbt resulted in a major difference in chromosomal structure: the AT-rich landscapes were mostly restricted to chromosome ends in Lml, Lbb or Lbt (Figure 3). Thus, within the species complex, only the Lmb genome had an isochore structure alternating large AT-rich and GC-equilibrated regions.

Repeat-masked nucleotide sequences of each genome were aligned with the others using MUMmer [35]. The genome alignment between the two Lmb isolates showed a perfect conservation of macrosynteny (Additional file 7: Figure S3A), as also observed by Ohm et al. [26] for isolates of Cochliobolus heterostrophus. Comparisons

Table 1 Sequencing statistics and genome statistics for six members of the Leptosphaeria maculans-L. biglobosa species complex

\begin{tabular}{|c|c|c|c|c|c|c|}
\hline & \multicolumn{2}{|c|}{$\begin{array}{l}\text { L. maculans } \\
\text { 'brassicae' }\end{array}$} & \multirow{2}{*}{$\begin{array}{l}\text { L. maculans } \\
\text { 'lepidii' } \\
\text { IBCN84 }\end{array}$} & \multirow{2}{*}{$\begin{array}{c}\text { L. biglobosa } \\
\text { 'brassicae' } \\
\text { B3.5 }\end{array}$} & \multirow{2}{*}{$\begin{array}{c}\text { L. biglobosa } \\
\text { 'canadensis' } \\
\text { J154 }\end{array}$} & \multirow{2}{*}{$\begin{array}{c}\text { L. biglobosa } \\
\text { 'thlaspii' } \\
\text { IBCN65 }\end{array}$} \\
\hline & v23.1.3 & WA74 & & & & \\
\hline Genome size (Mb) & 45.1 & 44.2 & 31.5 & 31.8 & 30.2 & 32.1 \\
\hline Contig number & 1743 & 3765 & 2802 & 2533 & 7124 & 3506 \\
\hline Scaffold number & 76 & 986 & 123 & 606 & 6748 & 237 \\
\hline Scaffold N50 (kb) & 1770 & 263 & 1356 & 779 & 245 & 715 \\
\hline Gaps (\%) & 2.5 & 9.6 & 7.1 & 7.4 & 0.1 & 8.7 \\
\hline Repeats (\%) & 35.5 & 27.5 & 4.0 & 4.4 & 3.9 & 5.1 \\
\hline Transposable elements (TEs) (\%) & 32.5 & 25.8 & 2.7 & 3.2 & 2.9 & 4.0 \\
\hline 'Ancestral' genome size $(\mathrm{Mb})^{\mathrm{a}}$ & 29.3 & 28.5 & 28.4 & 28.4 & 29.3 & 28.0 \\
\hline GC content of the whole genome (\%) & 45.2 & 46.5 & 50.9 & 51.4 & 51.1 & 51.4 \\
\hline GC 'ancestral' genome' (\%) & 51.6 & 51.6 & 51.6 & 52.0 & 51.6 & 52.1 \\
\hline GC content of TEs (\%) & 34.3 & 34.5 & 32.3 & 36.6 & 34.7 & 36.6 \\
\hline Predicted gene number & 12543 & 10624 & 11272 & 11390 & 11068 & 11691 \\
\hline
\end{tabular}

a`Ancestral genome' refers to the core genome without TEs. 


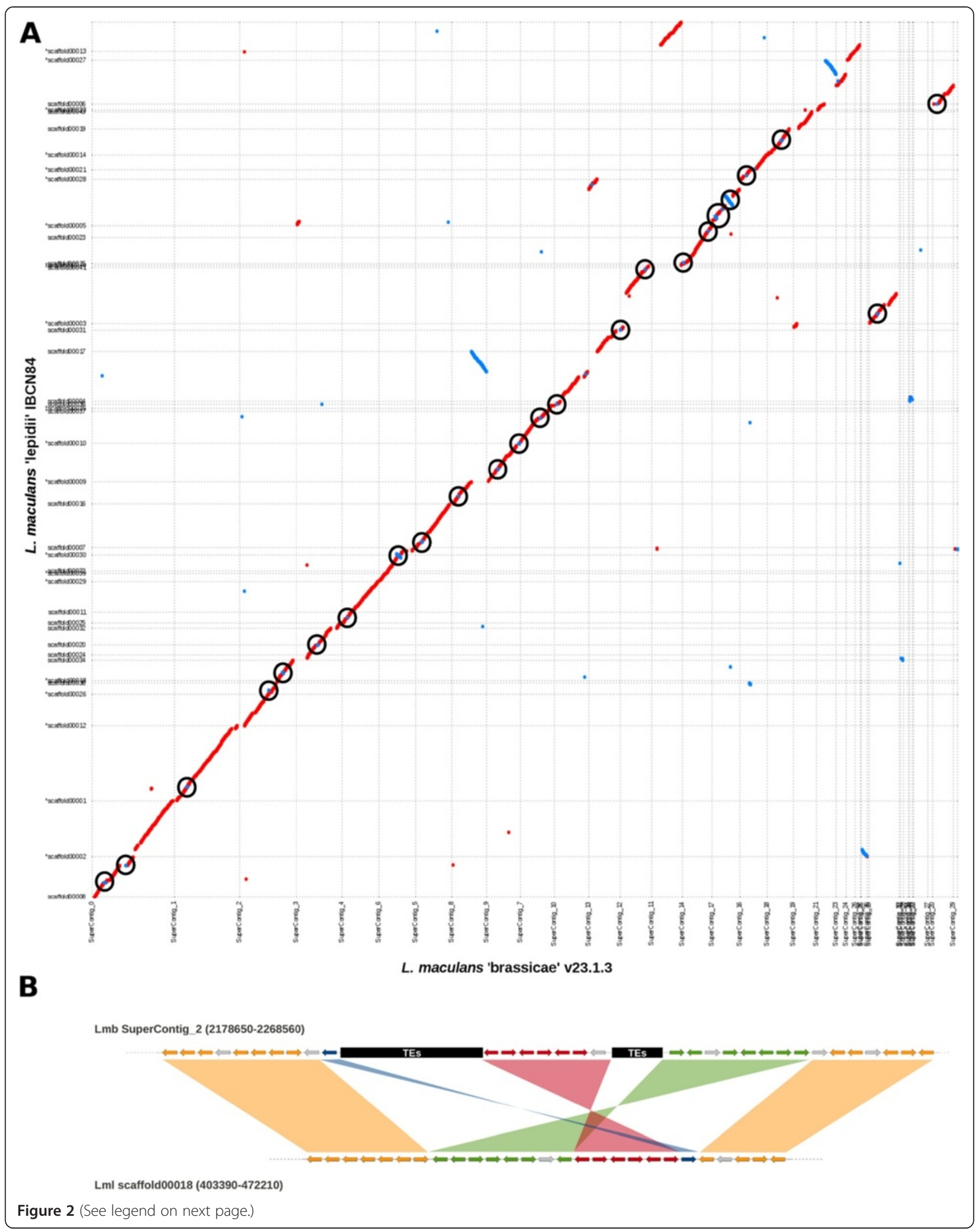


(See figure on previous page.)

Figure 2 Genome alignment and synteny analyses between L. maculans 'brassicae' (Lmb) and L. maculans 'lepidii' (Lml). (A) Whole genome dotplot showing intrachromosomal inversions occurring in the genome of $L$. maculans 'brassicae' (horizontal axis) compared to that of $L$. maculans 'lepidii' (vertical axis). Inverted regions are circled in black and the number of inversions is mentioned close to the circle. (B) Schematic zoomed representation of one SuperContig_2 region (in $\mathrm{Lmb}$ ) and its syntenic region in $\mathrm{Lml}$. The region contains three inversions and the location of bordering transposable elements in $\mathrm{Lmb}$ are indicated as black boxes. The arrows represent genes and their orientation. Genes with no orthologs are colored in grey.

between Lmb and Lbb genomes, or between Lmb and Lbt genomes showed a globally well-conserved synteny with many intrachromosomal inversions (Additional file 7: Figures S3C, S3D). The alignment between Lmb and the most closely related species, Lml, is of particular interest since it showed a highly conserved macrosynteny pattern with only few major genomic rearrangements (Figure 2; Additional files 7 and 8: Figures S3B, S6). While large scale translocations were not seen, 30 intrachromosomal sequence inversions sized from 1.3 to $355 \mathrm{~kb}$ were identified (median size: $9.5 \mathrm{~kb}$ ). These inversions were scattered along all the chromosomes and encompassed one to more than a hundred genes (Figure 2). The inversions within the chromosomes of the two isolates of Lmb analysed were bordered by TEs in $70 \%$ of the cases with TEs located at $82 \mathrm{bp}$ on average from the inversion breakpoints (Additional file 9: Table S4; Figure 2).

The alignments also allowed to infer the sequence polymorphism between the different members of the species complex. The two Lmb isolates had very similar genomes, only 20,404 SNPs have been identified in the aligned non-repetitive regions (Table 2). In spite of highly syntenic genomes, the number of SNPs between $\mathrm{Lmb}$ and Lml was ca. 1.5 million. A similar number of SNPs between aligned regions is found when comparing other members of the species complex one to another, suggesting that what have been previously considered as sub-species might actually be distinct species.

\section{Repertoire of transposable elements}

Even though TEs were highly degenerated by RIP, the use of the REPET pipeline followed by extensive manual annotation allowed identification and classification of a large proportion of the repeats present in the genomes of Lmb, Lml, Lbb and Lbt (Additional files 10 and 11: Tables S5, S6; Additional file 12: Supplementary Data 1). One hundred and twenty-one consensus sequences have been identified of which 69 (57\%) were classified as Class I or Class II TEs (Additional files 10 and 11: Tables S5, S6). Of these, 40 represented copy variants of TE families identified in several genomes and grouped into 16 larger families while the 29 remaining families were invariant between species (regardless of presence of RIP mutations).
TEs represented $c a .30 \%$ of the Lmb genome but only $4 \%$ and less in the other genomes (Table 1). Nevertheless, despite the major differences in genome coverage between Lmb and related species, a similar number of TE families $(\sim 30)$ were identified in each of the annotated genomes (Additional files 10 and 11: Tables S5, S6). Class I elements were the most abundant in all genomes (39.5 to $50.1 \%$ of the repetitive fraction in $\mathrm{Lml}$, Lbb, Lbc and Lbt genomes) and up to $83 \%$ of the repetitive fraction in the genome of Lmb (Table 3). Uncertainties remain due to the high proportion of non-categorized repeats in the genomes of Lml, Lbb, Lbc and Lbt (19.2$48.8 \%$ ) and higher proportion of unresolved nucleotides in the assemblies compared to the reference Lmb v23.1.3 (Table 1). Regardless of these uncertainties, our data support the fact that Lmb is an exception in terms of TEs and further indicate that the expansion of Class I TEs (mainly LTR retrotransposons) is remarkable in this species compared to related ones (Table 3).

\section{Evolutionary dynamics of transposable elements}

Previously, using an alignment-based phylogenetic approach with TE sequences deprived of the RIP-affected sites, we postulated that TE expansion in Lmb genome took place between 4 and 20 MYA for TEs such as DTM_Sahana, RLG_Rolly, RLG_Olly, RLG_Rolly and RLC_Pholy while others such as RLG_Dolly had been resident and maintained in the genomes for very long times ( $>100$ MYA) [9]. Mining for TE sequences in the entire Ascomycota phylum showed that TEs homologous to those present in the species complex were only found in class Dothideomycetes and were restricted to the order Pleosporales, with two exceptions, RLG_Dolly and DTT_Krilin, found in P. fijiensis a member of order Capnodiales (Figure 4; Additional file 13: Supplementary Data 2). As mentioned previously, this species, like $\mathrm{Lmb}$, is TE-rich and has a low GC-content (Additional file 4: Table S1).

According to the chronogram in Figure 1, these two TE families have been present in the dothideomycete lineage for at least 300 MYA. This assumption is consistent with previous data that suggested RLG_Dolly as the most ancient TE present in the Lmb genome [9]. However it remains uncertain whether these two TE 


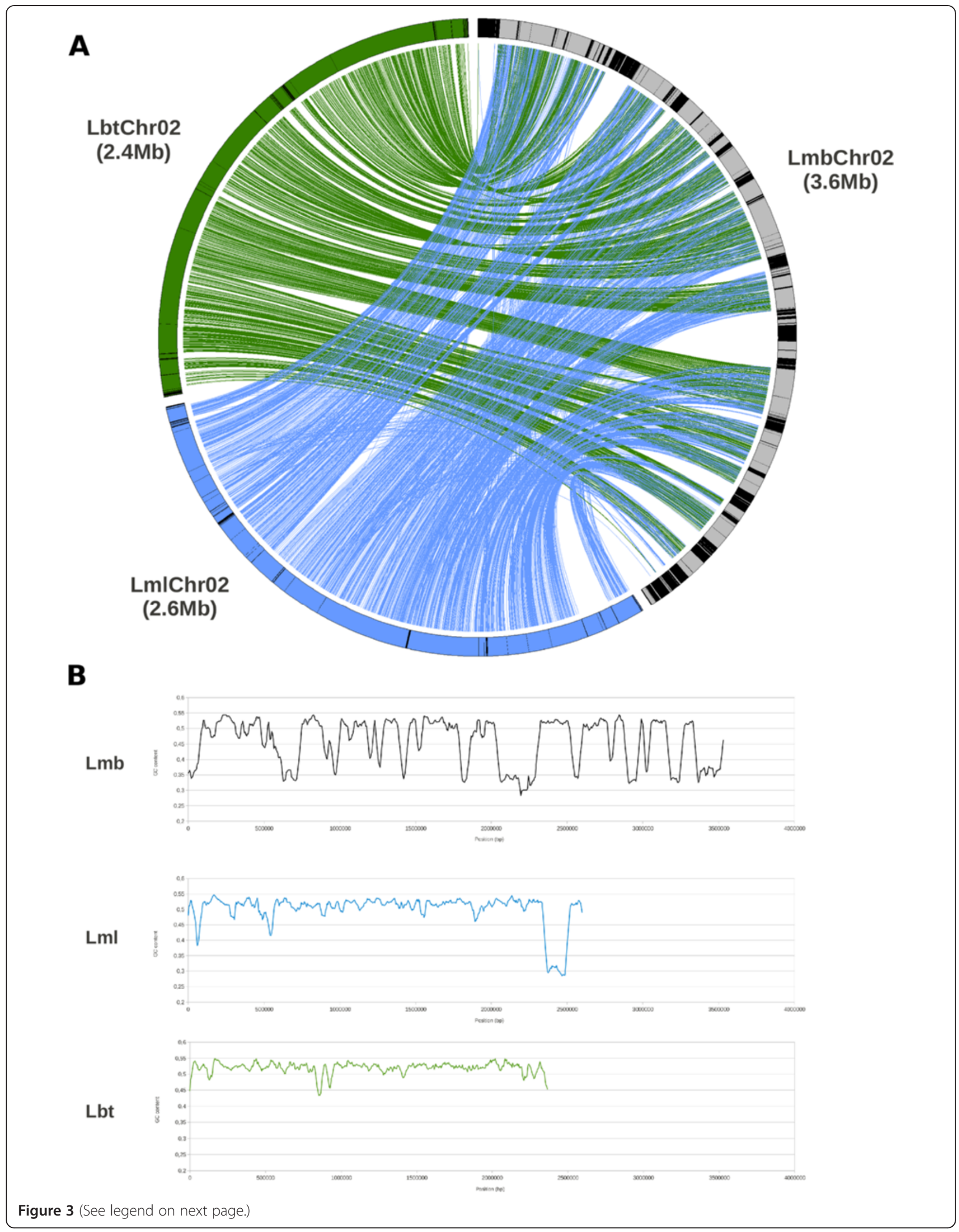


(See figure on previous page.)

Figure 3 Comparative chromosome structure in L. maculans 'brassicae' (Lmb), L. maculans 'lepidii' (Lml) and L. biglobosa 'thlaspii' (Lbt): the example of chromosome 2. (A) Circos representation of synteny between the homologous chromosomes. The black parts represent the TE-rich, AT-rich chromosomal regions; (B) GC content changes along the chromosomes showing the typical isochore structure of the L. maculans 'brassicae' chromosomes, absent form the other species.

families invaded the fungal genomes before the Capnodiales-Pleosporales separation and then were widely lost in the Capnodiales or if their presence only in P. fijiensis is incongruent with vertical inheritance.

The remaining TE families are likely to represent surges of genome invasion at different times before and after the divergence of the Pleosporales (Additional file 14: Figure S4; Additional file 13: Supplementary Data 2). Among all the TE families identified in the L. maculans-L. biglobosa species complex, $66 \%$ are specific to the species complex (Additional file 14: Figure S4; Additional file 13: Supplementary Data 2).

Class I elements often showed an erratic phylogenetic distribution and presence/absence patterns in terminal nodes or terminal branches of the phylogeny. In contrast, Class II elements generally were better conserved amongst the Pleosporales. In addition, complete copies of DNA transposons were often maintained in all species in which they were present while only truncated copies or small-sized remnants were present for many Class I elements (Additional file 13: Supplementary Data 2). For example, DTT_Molly (previously identified in Phaeosphaeria nodorum [36]) was present in all species of Pleosporales except the L. maculans lineage (Figure 4). In many cases, two closely related species were missing one well-conserved TE family, further exemplifying the highly dynamic gain and loss patterns of TEs (e.g. DTT_Finwe absent from Lbt, but present in other members of the species complex, or DTA_Kami absent from C. sativus, but present in C. heterostrophus (Additional file 13: Supplementary Data 2)). Lastly, some TE families (e.g. DTT_Yamcha in Lml and C. heterostrophus, or DTF_Elwe in Lmb and P. tritici-repentis) were only found in distantly related species of the Leptosphaeriaceae and Pleosporaceae. This indicates multiple losses, independent invasion of the genomes or horizontal transfer events (Additional file 13: Supplementary Data 2).

Transposable element dynamics in L. maculans 'brassicae' Fifty one families, mainly corresponding to non-categorized repeats, were specific to terminal branches of the species complex. The number of these families varied from $c a .10$ for the TE-poor genomes to 18 for the TE-rich Lmb genome, thus supporting the hypothesis of recent invasion of the Lmb genome by families of TEs absent from other members of the species complex. The presence of Lmbspecific TE families such as RLx_Ayoly (covering $400 \mathrm{~kb}$ of the genome of Lmb v23.1.3) and RLG_Rolly (covering $2.2 \mathrm{Mb}$ ) [9] (Figure 4; Additional files 1 and 8: Figures S1, S6) indicate a recent invasion of Lmb genome followed by a massive expansion of these families. Comparisons of the $\mathrm{TE}$ mosaics between the two isolates of Lmb showed that $61.5 \%$ of them are conserved indicating that this massive TE expansion occurred before, or at the onset of intraspecies divergence. In contrast, some families like DTM_Sahana showed highly diverse insertion patterns with only $12 \%$ of identical locations in the two Lmb genomes (Additional file 15: Table S7). This strongly suggests, as previously postulated [9] that DTM_Sahana is one of the most recent genome invaders and that waves of transposition activity took place after separation between the two Lmb isolates.

This simple picture indicating coincidence between genome invasion by new TE families and speciation becomes less straightforward when considering the three retrotransposons that account for most of the v23.1.3

Table 2 Alignment length and SNP counts between the genomes of members of the Leptosphaeria maculans-Leptosphaeria biglobosa species complex

\begin{tabular}{|c|c|c|c|c|c|c|}
\hline & & $\begin{array}{l}\text { L. maculans } \\
\text { 'brassicae' }\end{array}$ & $\begin{array}{l}\text { L. maculans } \\
\text { 'lepidii' }\end{array}$ & $\begin{array}{c}\text { L. biglobosa } \\
\text { 'brassicae' }\end{array}$ & $\begin{array}{l}\text { L. biglobosa } \\
\text { 'canadensis' }\end{array}$ & $\begin{array}{l}\text { L. biglobosa } \\
\text { 'thlaspii' }\end{array}$ \\
\hline & & \multicolumn{5}{|c|}{ Genome alignment length (Mb) } \\
\hline $\begin{array}{l}\text { L. maculans } \\
\text { 'brassicae' }\end{array}$ & & 20404 & 24.2 & 8.1 & 8.4 & 8.6 \\
\hline L. maculans 'lepidii' & & 1598215 & - & 8.2 & 8.6 & 8.7 \\
\hline $\begin{array}{l}\text { L. biglobosa } \\
\text { 'brassicae' }\end{array}$ & No. of SNP & 1095420 & 1104219 & - & 25.9 & 15.6 \\
\hline $\begin{array}{l}\text { L. biglobosa } \\
\text { 'canadensis' }\end{array}$ & & 1134785 & 1153336 & 1459160 & - & 16.3 \\
\hline L. biglobosa 'thlaspii' & & 1147859 & 1163826 & 1739473 & 1794939 & - \\
\hline
\end{tabular}


Table 3 Transposable element content in genomes of isolates of the Leptosphaeria maculans-Leptosphaeria biglobosa species complex

\begin{tabular}{|c|c|c|c|c|c|c|c|c|c|c|c|}
\hline \multirow[b]{2}{*}{ TE class } & \multirow[b]{2}{*}{ TE order } & \multicolumn{2}{|c|}{$\begin{array}{l}\text { L. maculans } \\
\text { 'brassicae' }\end{array}$} & \multicolumn{2}{|c|}{$\begin{array}{l}\text { L. maculans } \\
\text { 'lepidii' }\end{array}$} & \multicolumn{2}{|c|}{$\begin{array}{c}\text { L. biglobosa } \\
\text { 'brassicae' }\end{array}$} & \multicolumn{2}{|c|}{$\begin{array}{l}\text { L. biglobosa } \\
\text { 'canadensis' }\end{array}$} & \multicolumn{2}{|c|}{$\begin{array}{l}\text { L. biglobosa } \\
\text { 'thlaspii' }\end{array}$} \\
\hline & & $\begin{array}{l}\text { Bases } \\
\text { covered }\end{array}$ & $\begin{array}{c}\% \text { of } \\
\text { repetitive } \\
\text { fraction }\end{array}$ & $\begin{array}{l}\text { Bases } \\
\text { covered }\end{array}$ & $\begin{array}{c}\% \text { of } \\
\text { repetitive } \\
\text { fraction }\end{array}$ & $\begin{array}{l}\text { Bases } \\
\text { covered }\end{array}$ & $\begin{array}{c}\% \text { of } \\
\text { repetitive } \\
\text { fraction }\end{array}$ & $\begin{array}{l}\text { Bases } \\
\text { covered }\end{array}$ & $\begin{array}{c}\% \text { of } \\
\text { repetitive } \\
\text { fraction }\end{array}$ & $\begin{array}{l}\text { Bases } \\
\text { covered }\end{array}$ & $\begin{array}{c}\% \text { of } \\
\text { repetitive } \\
\text { fraction }\end{array}$ \\
\hline \multirow[t]{5}{*}{ Class I } & $\begin{array}{c}\text { Ty1-Copia } \\
\text { LTR }\end{array}$ & 3372500 & 22.1 & 77794 & 7.6 & 166805 & 14.9 & 34236 & 3.8 & 141432 & 10.0 \\
\hline & $\begin{array}{c}\text { Ty3-Gypsy } \\
\text { LTR }\end{array}$ & 8749750 & 57.4 & 426573 & 41.7 & 368819 & 32.9 & 399244 & 44.4 & 365617 & 25.7 \\
\hline & LINE & 6996 & 0.0 & 6523 & 0.6 & 15680 & 1.4 & 4535 & 0.5 & 54520 & 3.8 \\
\hline & Misc. & 586134 & 3.8 & 1552 & 0.2 & 0 & 0.0 & 0 & 0.0 & 0 & 0.0 \\
\hline & Sub-total: & 12715380 & 83.3 & 512442 & 50.1 & 551304 & 49.2 & 438015 & 48.7 & 561569 & 39.5 \\
\hline \multirow[t]{6}{*}{ Class II } & Tc1-Mariner & 36075 & 0.2 & 193492 & 18.9 & 157676 & 14.1 & 76864 & 8.5 & 136579 & 9.6 \\
\hline & hAT & 79154 & 0.5 & 1845 & 0.2 & 71796 & 6.4 & 21781 & 2.4 & 16950 & 1.2 \\
\hline & Mutator & 890076 & 5.8 & 22524 & 2.2 & 42470 & 3.8 & 1344 & 0.1 & 3957 & 0.3 \\
\hline & MITE & 0 & 0.0 & 11065 & 1.1 & 462 & 0.0 & 0 & 0.0 & 0 & 0.0 \\
\hline & Misc. & 336819 & 2.2 & 19579 & 1.9 & 81576 & 7.3 & 30251 & 3.4 & 8034 & 0.6 \\
\hline & Sub-total: & 1342124 & 8.8 & 248505 & 24.3 & 353980 & 31.6 & 130240 & 14.5 & 165520 & 11.6 \\
\hline \multirow[t]{2}{*}{$\begin{array}{l}\text { Non- } \\
\text { categorized }\end{array}$} & $\begin{array}{c}\text { Non- } \\
\text { categorized }\end{array}$ & 1199008 & 7.9 & 262241 & 25.6 & 215260 & 19.2 & 331133 & 36.8 & 694332 & 48.8 \\
\hline & Total: & 15256512 & & 1023188 & & 1120544 & & 899388 & & 1421421 & \\
\hline
\end{tabular}

genome expansion along with RLG_Rolly: RLC_Pholy (covering $3.1 \mathrm{Mb}$ ), RLG_Polly (covering $3 \mathrm{Mb}$ ) and RLG_Olly (covering $3 \mathrm{Mb}$ ) [9]. These three retrotransposons have been present in the Pleosporales phylogeny for at least 90 MYA, but they only represent a little fraction of the genomes of other Pleosporales species or other members of the species complex to-date (Figure 4; Additional file 13: Supplementary Data 2).

Classification of the TEs in families and phylogenetic analyses further indicated that the TEs associated with intrachromosomal inversions (Additional file 9: Table S4) between Lmb and Lml were mainly L. maculans- and even Lmb-specific TEs, i.e. recent TE-invaders such as DTM_Sahana or RLx_Ayoly (Additional file 9: Table S4).

\section{Gene conservation}

Of the 57,964 proteins predicted in the Leptosphaeria species complex, $75 \%$ were grouped into 10,131 families using orthoMCL [37]. Then, the core proteome of the sequenced species, encompassing 6735 proteins, was established (Figure 5).

To identify species-specific proteins, all the proteins that were not grouped into the 10,131 families were compared by BLAST at the nucleotide (BLASTn) and protein level (tBLASTn) against the other genomes and at the protein level (BLASTp) against the set of ungrouped proteins of the other species. The analysis allowed us to discriminate three classes of protein sequences: (i) species-specific sequences, (ii) sequences present in at least one other species and (iii) sequences for which presence or absence remained unresolved with our criteria (Additional file 16: Table S8). In addition, the occurrence of pseudogenes was investigated when lack of matching predicted protein sequence was associated with BLASTn or tBLASTn hits (Additional file 16: Table S8).

Each genome shared on average 10,400 proteins with (at least one of) the others, which represents 84.4-93.7\% of the predicted proteins depending on the species. Usually, these sequences were conserved in organisms outside of the species complex since $74.3-85.5 \%$ of them have homologies in the NR database or harbour known protein domains. The remaining species-specific proteins, which represented $4.8-10.7 \%$ of the genomes (Additional file 16: Table S8) had very few predicted functions since 93.6-97.8\% of them had no automated functional annotations. As a consequence, explaining species-specific biological or pathogenicity traits was not straightforward. However, two categories of species-specific genes could be identified and are analysed in more details below: genes encoding putative effectors and cluster of genes encoding secondary metabolites.

Interestingly, the Lmb genome was more enriched in specific sequences than all other members of the species complex and these genes were located in AT-isochores: $25.6 \%$ of the 620 genes of Lmb located in AT-isochores were species-specific, compared to only $9.8 \%$ of the genes located in GC-isochores. 


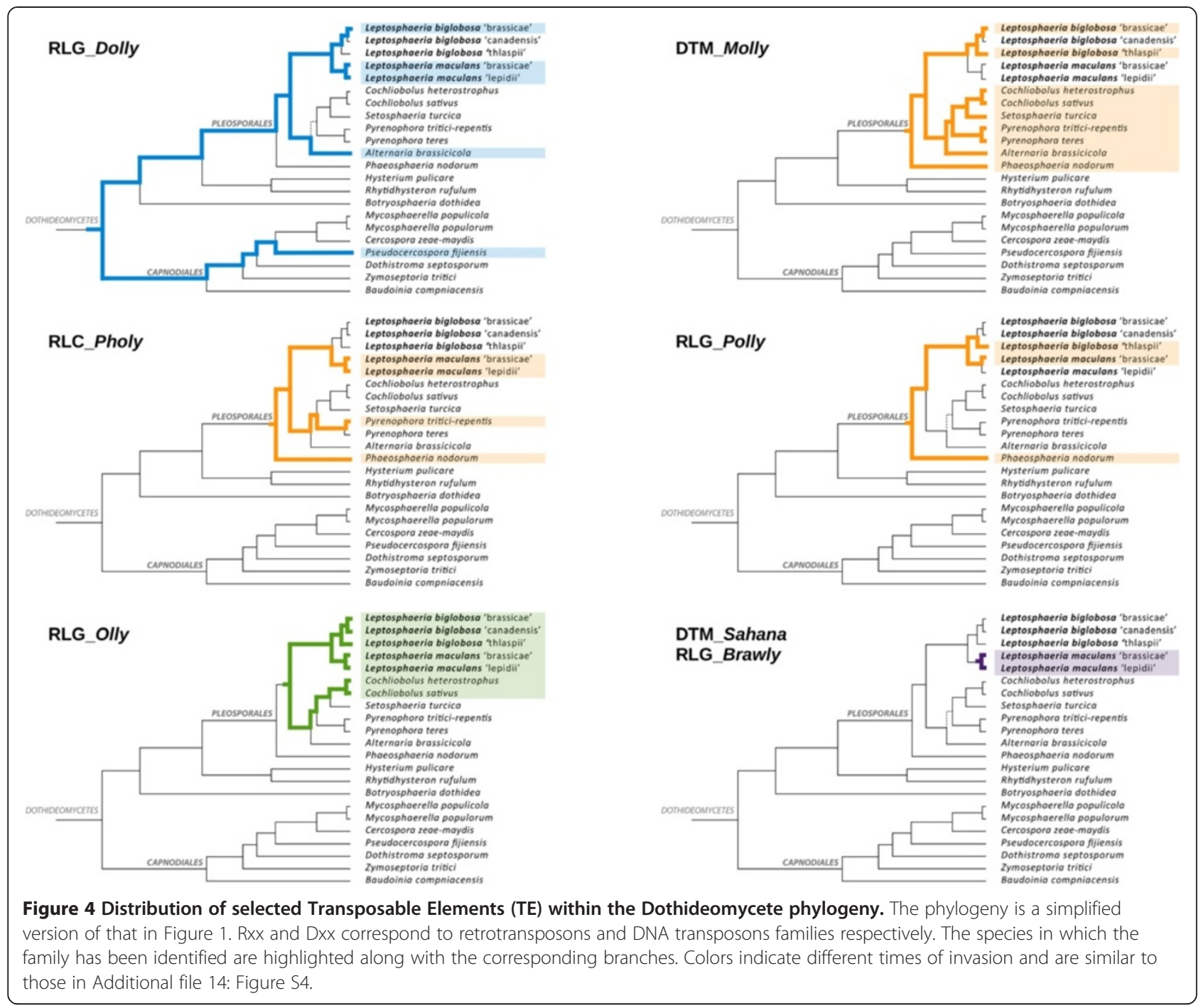

\section{Pathogenicity gene analysis: effectors and secondary metabolites \\ Candidate effectors (small secreted protein)}

The number of Small Secreted Proteins (SSPs) amongst the whole predicted proteome of each genome was similar in all the sequenced Leptosphaeria genomes, ranging from 621 in Lbc to 737 in Lml. They represented ca. 6\% of the predicted proteins and $60 \%$ of the predicted secretome of each genome. Their features (153 amino acids on average; 2.8 times as rich in cysteine residues as other proteins in the genomes) were very similar in all Leptosphaeria isolates (Table 4). Their encoding genes were scattered along the chromosomes and had a similar GC-content ( $52 \%)$ not different from the other predicted genes of the genomes (Table 4). However, as previously found, GC content varied as a function of genome location, and SSP genes in AT isochores had an average $48.2 \%$ GC content [9].
The repertoire of SSP-encoding genes appeared to be in part extremely plastic and its conservation was consistent with phylogenetic distance with $73.8 \%$ of the SSP-encoding genes of v23.1.3 conserved in the other Lmb isolate, WA74, 54.2\% conserved in Lml, and 42.5 to $44.0 \%$ conserved in L. biglobosa isolates (data not shown). In the core proteome, $20 \%$ of SSPs have a predicted function, and may relate to factors linked with pathogenicity such as carbohydrate-degrading enzymes (CAZys). However, the greater was the species-specificity, the less obvious was the potential function of SSP-encoding genes.

SSP-encoding genes did not generally occur as multigene families in the L. maculans-L. biglobosa complex, but a few of them (less than ten) had paralogs, usually conserved in all genomes. They corresponded to proteins usually belonging to multigenic families such as CAZys and were mainly located in GC-isochores in the Lmb genome. Only one effector gene with avirulence activity had an easily 


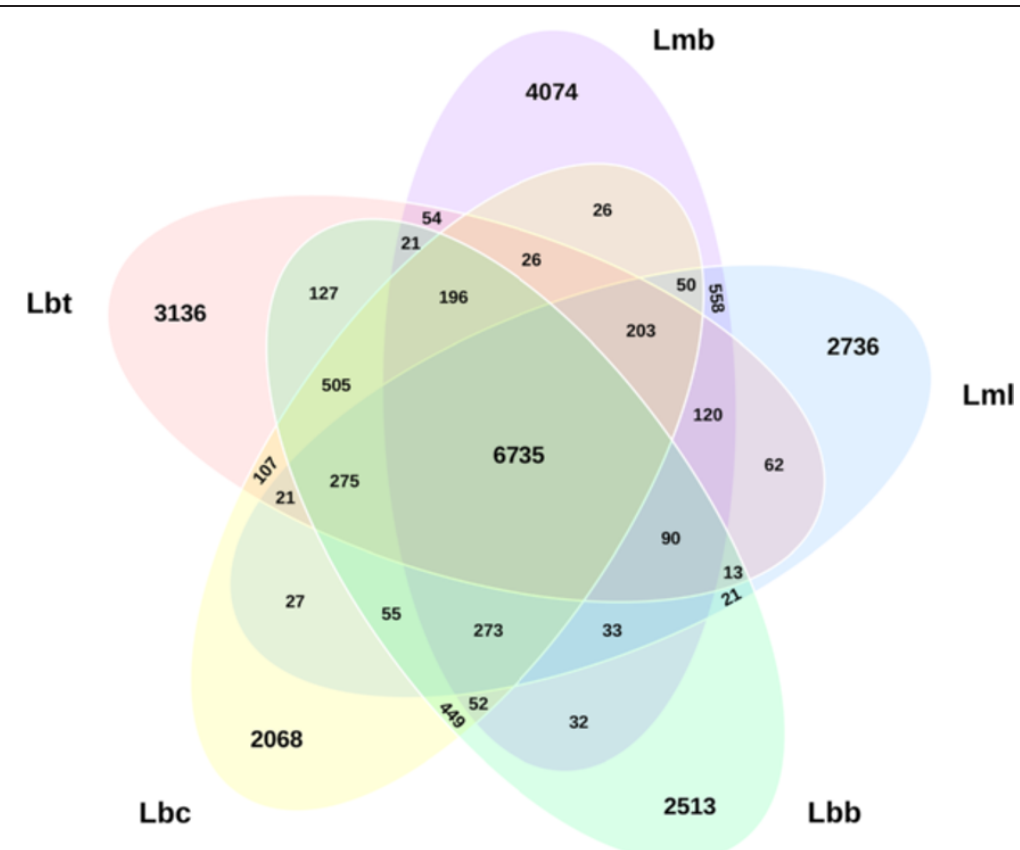

Figure 5 Conservation of protein-encoding genes in the Leptosphaeria maculans-L. biglobosa species complex. Lmb, L. maculans 'brassicae'; Lml, L. maculans 'lepidii'; Lbb, L. biglobosa 'brassicae'; Lbt, L. biglobosa 'thlaspii'; Lbc, L. biglobosa 'canadensis'.

recognisable paralog in the Lmb genome: AvrLm4-7 located within an AT-isochore had a paralog located $30 \mathrm{~kb}$ upstream on the same chromosome.

\section{Avirulence effectors}

Seven SSP genes conferring an avirulence phenotype on a series of genotypes of Brassica spp., i.e. interacting in gene-for-gene interactions with the plant surveillance machinery, have been cloned in Lmb. All are located in AT-isochores, and they generally showed a high level of diversification compared to their closest homologs (rarely above $30 \%$ sequence identity at the amino acid level), while usually maintaining a specific pattern of cysteine spacing (Additional file 17: Figure S7). They mostly showed a patchy distribution along the phylogenies or were specific to a few members of the species complex. Six of these had recognisable homologs in other fungal genomes:

AvrLmMex (A. Degrave, unpublished data) and AvrLm11 [15] are specific to the Leptosphaeriacae, with AvrLmMex having homologs in every member of the species complex except Lml (Additional file 18: Table S9). The AvrLm11-

Table 4 Characteristics of genes encoding Small Secreted Proteins (SSPs) and other predicted proteins in isolates of the Leptosphaeria maculans-Leptosphaeria biglobosa species complex

\begin{tabular}{|c|c|c|c|c|c|}
\hline & $\begin{array}{l}\text { L. maculans } \\
\text { 'brassicae' }\end{array}$ & $\begin{array}{l}\text { L. maculans } \\
\text { 'lepidii' }\end{array}$ & $\begin{array}{l}\text { L. biglobosa } \\
\text { 'brassicae' }\end{array}$ & $\begin{array}{l}\text { L. biglobosa } \\
\text { 'canadensis' }\end{array}$ & $\begin{array}{l}\text { L. biglobosa } \\
\text { 'thlaspii' }\end{array}$ \\
\hline No. of SSPS & 651 & 737 & 665 & 621 & 676 \\
\hline SSPs mean size (aa) & 155.9 & 144.8 & 153.8 & 157.4 & 152.9 \\
\hline All predicted proteins mean size (aa) & 416.5 & 427.4 & 434.6 & 464.2 & 421.0 \\
\hline \%Cys in SSPs & 3.10 & 2.75 & 2.60 & 2.86 & 2.79 \\
\hline$\%$ Cys in all predicted proteins & 1.69 & 1.46 & 1.45 & 1.42 & 1.48 \\
\hline$\% G C$ in SSP genes & 53 & 51 & 53 & 52 & 53 \\
\hline$\%$ GC in all predicted genes & 53 & 53 & 54 & 53 & 54 \\
\hline RIP index ${ }^{a}$ in SSP genes & 1.22 & 1.23 & 1.15 & 1.04 & 1.16 \\
\hline RIP index in all predicted genes & 1.04 & 1.02 & 1.01 & 0.89 & 1.01 \\
\hline$\% \mathrm{TpA} / \mathrm{ApT}>=1.5$ in SSP & 18.4 & 19.4 & 13.5 & 8.2 & 15.5 \\
\hline$\%$ TpA/ApT > =1.5 in all predicted genes & 7.0 & 5.0 & 4.1 & 1.7 & 4.2 \\
\hline
\end{tabular}

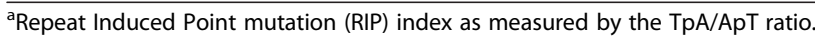


encoding gene is located on a conditionally dispensable chromosome (CDC) present in some isolates of Lmb and absent from other isolates of the species complex [15]. AvrLm11, however, showed homologies with a SSP predicted in the Lbt genome (Additional file 18: Table S9) while three additional genes of the CDC also had orthologs in the genome of Lbt. These three genes were grouped in the Lbt genome at a different location to that of the AvrLm11 homolog.

Sequences related to AvrLm1 [12] and AvrLm4-7 [14] were in a few species of class Dothideomycetes only. An AvrLm1 homolog was in the set of predicted proteins of Lbt but not in other members of the species complex (Additional file 18: Table S9). Interestingly, the orthologous gene was also located in a large but poorly assembled AT-rich region, devoid of other predicted genes. Both AvrLm1 and its Lbt ortholog showed homology with two SSPs with unknown function in the Pleosporales species Pyrenophora teres $f$. teres (Additional file 18: Table S9).

As described above, AvrLm4-7 had a paralog in the Lmb genomes ( $L m C D S 2,65.5 \%$ of identity at the nucleotide level). This duplication did not occur in the other members of the species complex since either AvrLm4-7 or LmCDS2 had one-copy homologs in these genomes (Additional file 18: Table S9). Outside of the species complex, AvrLm4-7 or LmCDS2 had homology with two SSPs with no predicted function of the Botryosphaeriales species Macrophomina phaseolina (Additional file 18: Table S9).

In contrast to the previous examples, AvrLm6 [13] and Lema_P086540.1 (A. Degrave, unpublished data) had homologs outside of the Dothideomycetes, but only in a few species of class Sordariomycetes (Additional file 18: Table S9). Within the species complex, these two proteins had SSP orthologs in Lml and Lbt (Additional file 18: Table S9).

\section{Secondary metabolite gene clusters}

Similar to genes encoding effectors, secondary metabolite biosynthetic genes such as Non-ribosomal Peptide Synthase (NPS) and Polyketide Synthase (PKS) genes showed examples of extreme specificity of occurrence and complete conservation within the species complex. NPSs and PKSs are multimodular genes that are keys in the biosynthesis of secondary metabolites. These genes are usually organised in clusters that include genes encoding enzymes such as methyl transferases, cytochrome P450 monooxygenases, hydroxylases that modify pathway intermediates. A total of 17 NPS genes were identified across the five members of the species complex (Figure 6A, Additional file 19: Table S10) and most (10) were shared by all five. SirP, the NPS involved in the production of the epipolythiodioxopiperazine toxin, sirodesmin PL [38], is only found in Lmb and Lml, which is relevant with biological data since L. biglobosa spp. do not produce this toxin. Globally, the distribution of NPS was well conserved between species in final branches (Lmb-Lml and Lbb-Lbc), whereas Lbt had an intermediate pattern of NPS. The species-specific NPSgenes in the complex may be the results of horizontal gene transfer or newborn pathogenicity determinants (Additional file 20: Supplementary Data 3).

Unlike the situation with NPS genes, there was a high degree of diversity in number and types of PKS genes identified across the members of the species complex (Figure 6B, Additional file 21: Table S11). In addition, and except for the examples mentioned below, homologs of PKSs were rare or absent in other Dothideomycetes and often had closest relatives in Sordariomycetes such as Fusarium spp. or Colletotrichum spp., or in Aspergilli (Additional file 20: Supplementary Data 3). A total of 31 PKS genes were identified of which only six were found in all species. Lmb and Lml had a very similar complement of PKS genes with 15 PKS in Lmb and only two missing in Lml, one of which was truncated. Twentythree different PKSs were in L. biglobosa species and several of them were species-specific: six were only found in Lbt which reflects the distinctiveness of Lbt from other members of the species complex (Figure 6B).

The PKS and NPS biosynthetic gene clusters conserved between Lmb and Lml and between Lbb and Lbc displayed a high level of synteny (data not shown). Of the 16 clusters conserved in all the sequenced members of the species complex, eight were embedded in highly syntenic regions. This included genes widely conserved in the Dothideomycetes (PKS4, PKS7, PKS10, NPS4, NPS6, and Lys2), and also NPS1 and NPS11 that are only conserved within the species complex. In the eight other cases, secondary metabolite clusters showed microsynteny in Lmb and $\mathrm{Lml}$, while they were reorganized in Lbb and Lbc. Once again, Lbt showed an intermediate genomic pattern with some clusters being syntenic with those present in Lmb and Lml (e.g. PKS3 or PKS15) and some clusters showing microsynteny with Lbb and Lbc (e.g. PKS8 or PKS9; data not shown).

Horizontal gene transfer has been proposed for the discontinuous distribution of several fungal secondary metabolite gene clusters $[20,39]$ and a clear example of this is seen in the situation of PKS21. Amongst the five species, this PKS was only present in Lbb, and reciprocal best matches showed that it had $>90 \%$ identity at both the nucleotide and protein level to a PKS from a very distantly related fungus, the eurotiomycete, Arthroderma otae, which is a dermatophyte (Figure 7). The five upstream genes showed high sequence similarity ( $>88 \%$ amino acid identity and $83 \%$ nucleotide identity) to genes upstream of the $A$. otae PKS, although this 


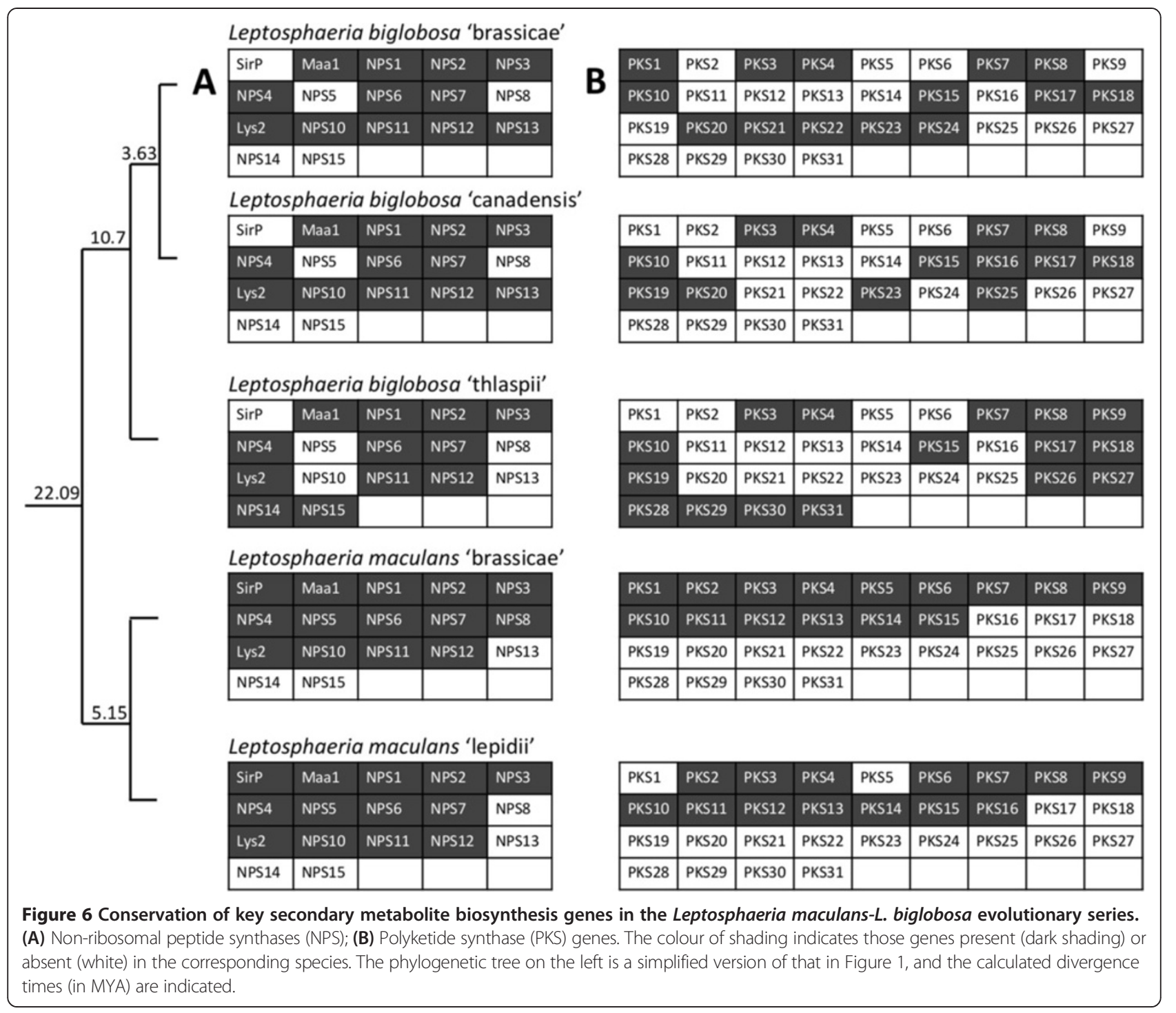

microsynteny was interrupted by the presence of three genes in A. otae. Several of the homologous genes had predicted functions consistent with biosynthesis of a secondary metabolite (Additional file 22: Table S12). Genes downstream of PKS21 in Lbb were also present in genomes of some of the other Leptosphaeria species (Figure 7).

\section{Transposable elements and pathogenicity genes}

Of the 620 genes located in AT-isochores in the Lmb genome, 148 genes (24\%) were surrounded by TEs (within $2 \mathrm{~kb}$ of 5 ' and 3' ends of genes), whereas the others were located at the transitional regions between AT- and GCisochores. Among these genes, 45 were conserved in other members of the species complex. In order to know if these genes were already present at the same location before the TE expansion, we investigated whether the region containing these genes and their closest flanking genes in Lmb were syntenic in the other genomes. For six genes, this analysis was impossible due to scaffolding differences of the assembly of the other genomes. For the remaining 39 genes, 26 did not encode SSPs and $81 \%$ of them showed a conserved microsynteny in the other genomes of the species complex, suggesting that the TE expansion did not influence the organisation of these small regions. Among the 13 genes encoding SSPs, six genes (46\%) were not colocalized with their flanking genes while these latters were, suggesting that those six genes were translocated within the genome. Strikingly, five of these six translocated genes were characterized avirulence genes: AvrLm6, AvrLm4-7, AvrLm11, AvrLmMex, and Lema_P086540.1. Furthermore, a sixth avirulence gene, AvrLm1, was present in the 45 genes analyzed but could not be analyzed further due to poor assembly of its region in Lbt 


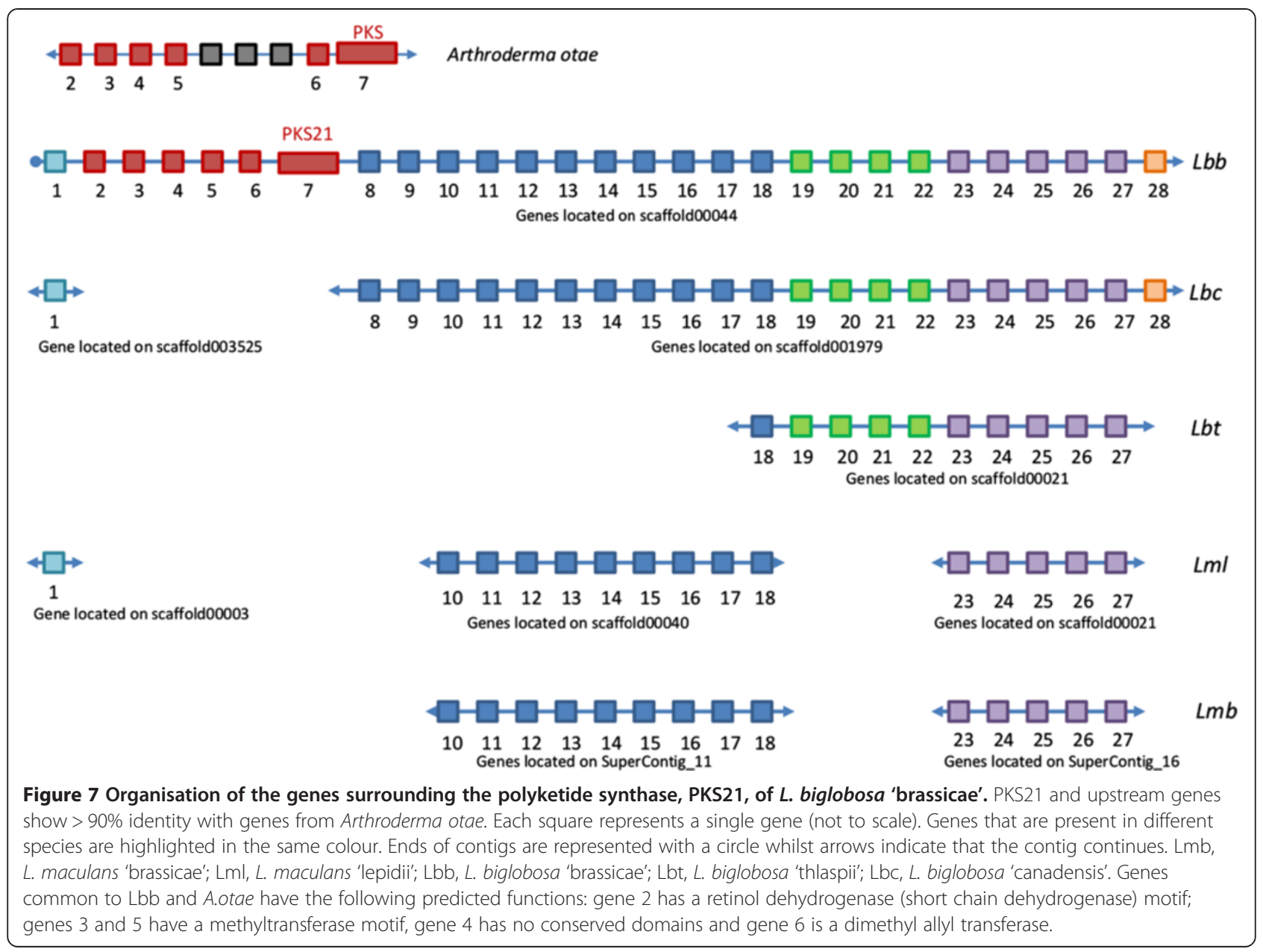

where it is likely to be hosted in an AT-rich genome environment.

Microarray and RNA-seq data were generated to identify the top 100 genes produced in planta, during the primary infection stage, by two species able to infect oilseed rape plants: Lmb and Lbb. Among the top 100 genes expressed at seven days post inoculation, 45\% encoded SSPs in the Lmb genome, whereas this proportion decreases to 21\% for Lbb (Additional file 23: Supplementary Data 4). Of these SSP-encoding genes, 30\% represent species-specific genes in Lmb genome, with very few (or none) are species-specific genes in Lbb.

RNA-seq gene expression values for Lmb and Lbc orthologs were coupled with proximity of TEs in the gene environment. Orthologous genes of Lmb and Lbc are more highly up-regulated in planta (on average) when a TE is located close to their promoter, than when it is not nearby (Figure 8).

\section{Discussion}

In this study, we used comparative genomic approaches to reassess speciation issues in the $L$. maculans-L. biglobosa species complex and to evaluate the role of TEs in genome reshaping and the rise of species with improved pathogenic abilities. Our data demonstrate that (i) each entity of the species complex actually is a distinct species; (ii) TEs likely contributed to speciation by generating chromosomal inversions; (iii) TE invasions/burst are recent at the evolution scale; (iv) TEs contributed to build two-speed genomes and most likely to translocate effector genes within plastic regions of the genome, with consequences on gene diversification, better adaptation to selection pressure and gene expression. All in all, TE bursts and their consequence on genome structure favored adaptation and pathogenicity towards oilseed rape by allowing generation of novel effector genes and their concerted expression during the first steps of plant infection.

\section{Reassessing speciation within the $L$. maculans $-L$. biglobosa species complex}

Fungi are estimated to include over 1.5 million species [40]. Their description and classification have been long 


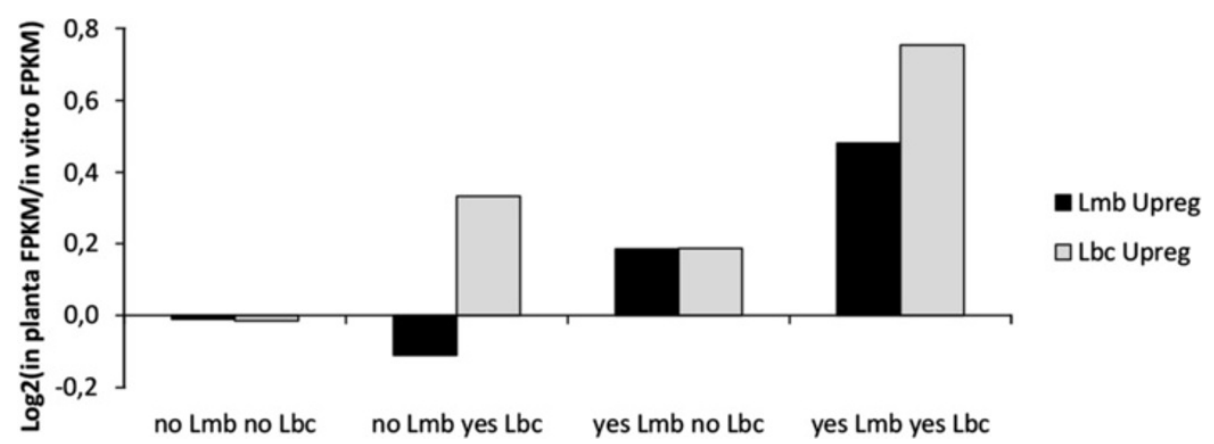

Figure 8 Effect of presence of repetitive element adjacents to promoter of orthologs on gene expression in planta compared to in axenic culture. In planta upregulation ratio (Log2(in planta FPKM/in vitro FPKM)) calculated from RNA-seq data for orthologs in L. maculans 'brassicae' (Lmb) and L. biglobosa 'canadensis' (Lbc) during growth in planta and in vitro. Ortholog pairs were categorised according to the presence or absence of repeat elements adjacent to the promoter region of both genes. Positive up-regulation ratios indicate higher expression during growth in planta. The categories were: no $\operatorname{Lmb}$ no $L b c(n=6959)$, no $L m b$ yes $L b c(n=60)$, yes $L m b$ no $L b c(n=382)$, yes $L m b$ yes Lbc $(n=14)$.

based on macro- or microscopic criteria, such as morphology or reproduction mode. The availability of genomic data for a large number of fungal species has allowed the inference of new phylogenetic relationships between close or even unrelated taxa previously aggregated in the same genera. This is exemplified by the Mycosphaerella genera and its new classification [41,42]. Here, we firstly re-investigated speciation issues in the $L$. maculans- $L$. biglobosa species complex based on sequence data analyses. The estimated divergence times between the terminal clades (5.1 MYA between Lmb and Lml and 3.6 MYA between Lbb and Lbc) are consistent with divergence time between species in closely related genera (Cochliobolus sativus and C. heterostrophus: 4.3 MYA, Mycosphaerella populicola and M. populorum: 4.7 MYA, Coccidioides posadasii and C. immitis 5.1 MYA [43]) (Additional file 2: Figure S2) and strongly indicate all Leptosphaeria isolates analysed here belong to different species. This hypothesis is supported by high numbers of SNPs (ca. 1.5 million) detected between each lineage of the species complex, which are in a comparable order of magnitude than those observed between different species of Cochliobolus [44] Further support for this hypothesis is provided by the degree of mesosynteny, i.e. the conservation within chromosomes of gene content but not order or orientation, between the members of the species complex [45]. Mesosynteny, firstly identified in Dothideomycetes, was recently postulated to be a mode of chromosomal evolution specific to fungi [45]. Comparative analyses of 18 dothideomycete species, and a simulation-based approach indicated that serial random inversions within the chromosome lead with time to extensive reshuffling of gene order within homologous chromosomes from one species to a distantly related one [26]. Focusing on relatively short divergence times, our analyses are consistent with this modelling-based hypothesis.
The number of genome rearrangements (30) between $\mathrm{Lmb}$ and Lml is many fewer than what has been reported between Cochliobolus sativus and C. heterostrophus, where there were as many as 30 inversions in a single scaffold [26]. This represents an earlier step towards mesosynteny than what was described for the Cochliobolus species.

\section{TE regulation in ascomycete genomes}

Sequencing confirmed that the genome of Lmb contains a larger proportion of TEs than those of the other members of the species complex, but also those of other Pleosporales. Heavily TE-invaded genomes can be found in ascomycetes such as Blumeria spp., in basidiomycetes or in oomycetes $[8,46]$. Often related species all show heavily TE-invaded genomes as exemplified by downy mildew fungi or rust fungi $[8,46]$. An intermediate situation is found in fungi in order Capnodiales of the Dothideomycetes that have a series of distantly related species with either TE-poor or TE-invaded genomes [26,31]. Compared to these examples, Pleosporales are an exception since all species sequenced to-date, including those of the species complex sequenced here show TE-poor genomes and TE expansion is only observed in Lmb.

In Phytophthora spp. and downy mildew fungi, the absence of irreversible defense systems able to regulate the TE activity results in an evolutionary trade-off in which the fitness cost linked with genome "obesity" eventually counter-selects individuals for which the fitness deficit is higher than the selective advantage conferred by enhanced genome plasticity. Compared to the Blumeria or Phytophthora examples, the expansion of TEs in the genome of Lmb (as in that of many other ascomycetes) remains limited (36\% of the genome for Lmb vs. $64 \%$ of the genome for B. graminis and $74 \%$ for P. infestans [8]). These data question about how TEs were controlled 
through time by Lmb and, in general, by most ascomycete species.

RIP is likely the most efficient genome defense mechanism against TEs and has been experimentally demonstrated to be currently active in L. maculans [47]. Evidences for past or current RIP activity has been reported in most ascomycete species, suggesting that RIP is an ancestral mechanism common to (at least) ascomycete fungi [48], with occasional patterns of secondary losses like observed in Blumeria spp. [33]. Since RIP induces irreversible changes in TEs, thus disabling their transposition mechanisms, it is therefore confusing how massive transposition activity could have taken place recently in Lmb genome for LTR retrotransposon families potentially present in the Pleosporales lineage since 100 millions years. Our data suggest that these TE families were not inactivated by RIP or that they were reactivated. Three main and complementary hypotheses, discussed below, could explain these data: (i) loss and regain of RIP activity with involvement of another epigenetic mechanism to control TE transposition events, (ii) biological traits preventing RIP activity, i.e. absence of sexual reproduction and (iii) recent and massive events of horizontal transfer (HT).

(i) Other inactivation mechanisms, also linked to the sexual cycle, have been described in Fungi such as methylation induced premeiotically (MIP) in the ascomycete Ascobolus immersus [49] and in the basidiomycete Coprinus cinereus [50]. MIP is an epigenetic mechanism which methylates but does not irreversibly mutate duplicated sequences. The fact that it is conserved between ascomycetes and basidiomycetes, raises the possibility that RIP evolved from MIP or from a similar silencing process [11]. The breakdown of such genome defense mechanism seemed to be linked with bursts of transposition in many species, resulting in genome rearrangements and eventually speciation [51]. Thus, we can hypothesize that a reversible epigenetic mechanism was previously active in Lmb genome and relieved under a stress-inducing event at the time of speciation, leading to the unleashing of transposition activity. The fact that all TE families are affected by RIP (none active TE copies in Lmb genome) suggests that epigenetic mechanisms were replaced by RIP as an irreversible control mechanism.

(ii) RIP is only active during meiosis, therefore prolonged growth in absence of sex would prevent RIP inactivation of TEs. Lmb undergoes prolific sexual reproduction [12], but asexual populations exist that are either adapted to other crucifers such as cabbage or present in environments where short growth season of the host plant prevent the fungus from completing its sexual cycle $[52,53]$. Asexual growth could also be imposed within a founder population with only one mating type. We can thus hypothesize that the rise of the Lmb species was followed by a long phase of asexual behaviour in order to propagate rapidly the newly-born species, without preventing expansion of TEs until sexual reproduction became prevalent with the need to diversify genotypes to adapt changing environmental conditions. Under this hypothesis, the other members of the species complex known to also use profusely sexual reproduction (e.g. Lbb in Europe or Lbc in Australia) never had such a long phase of asexual behaviour and efficiently limited TE expansion using RIP.

(iii) TEs can invade a genome through HT $[54,55]$ and, in animals, arthropods vectors are allowing HT between species [55]. Microbes sharing the same diverse ecological niche with Lmb (soil, stem residues, leaf surfaces, plant tissues), but whose biodiversity is currently unexplored, or the host plants themselves are candidates vectors for such HT of TEs to Lmb genome. Our phylogenetic analyses did not allow us to establish whether such HT events occurred in the dothideomycete phylogeny, but multiple cases of patchy distribution of TE families do not contradict this hypothesis. In addition, even with RIP being active and occurrence of sexual reproduction, constant donation of TEs could occur from a donor that was present over an extended period of many million years, such as a virus or an intracellular symbiotic bacteria [56]. The donor TEs would not be affected by RIP, as it is protected in the vector, but each new introduction would be RIPed and inactivated as it arrived. Long term addition could result in the establishment and the expansion of TE-rich regions. We acknowledge that this is extremely speculative, as currently massive and recent introduction and expansion of TEs cannot be distinguished from multiple introductions, due to extensive sequence degeneracy following RIP.

\section{Speciation and TE expansion}

In many eukaryotic lineages, links between bursts of transposition and speciation are observed, but it is difficult to determine whether these bursts were responsible for speciation or if they were a consequence of it [51]. In this study, two events were predicted to have taken place during the same period of time: (i) the speciation event separating Lmb from Lml and (ii) the introduction in the Lmb genome of new TE families followed by the expansion of ancient and recent TE famillies. The effects of invasion by species-specific TEs on speciation events are difficult to sort out since introduction of new TE families were observed several times during evolution within the dothideomycete lineage while bursts of transposition did not occur in any other Pleosporales species. However, the analysis of TE distribution was based only on TEs identified in the members of the $L$. maculans- $L$. biglobosa species complex, which precluded inference of relationships between TEs and speciation in the other Pleosporales genera. Moreover, as mentioned previously, the patchy distribution of some TE families, especially 
LTR retrotransposons, could be evidence of HT of TEs between species [57] and thus disrupt the evolutionary history of these elements. In Lmb 70\% of the intrachromosomal inversions were bordered by TEs specific to the L. maculans clade. Ohm et al. [26] suggested that inversion breakpoints in dothideomycetes genomes were associated with Simple Sequence Repeats (SSR), a feature that was not apparent when comparing Lmb and $\mathrm{Lml}$ genomes. These data may indicate a major role for TEs rather than SSRs in genome reshaping and reshuffling at the chromosomal level, similar to the documented incidence of TEs on chromosomal inversions in more complex Eukaryotes such as Drosophila [58] or mammals [59]. This first step towards mesosynteny clearly ascribes a role to species-specific TEs in this evolutionary mechanism that will eventually generate non-homologous sections of chromosomes and isolate part of the genome from meiotic recombination.

\section{Can genome data explain biological and phytopathological specificities?}

TEs are involved in adaptation of phytopathogens to new hosts by promoting HGT, as exemplified by the transfer of a host selective toxin, ToxA between Phaeosphaeria nodorum and Pyrenophora tritici-repentis, thus generating a new disease because of better adaptation of strains of $P$. tritici-repentis to their host plant, wheat [60]. TEs also promote the birth of new pathogenicity traits via gene duplication and translocation eventually generating large multigene families of effectors as exemplified by the downy mildew fungi and Phytophthora species $[8,33]$.

Our data were indicative of HGT between phylogenetically divergent species mostly for secondary metabolite gene clusters, of which some species-specific are located within AT isochores in Lmb, but information on the involvement of TEs in these HGT phenomena were sparse. Such HGT is seen in another member of the species complex, Lbb, in the situation of PKS21 and surrounding genes of the cluster only found in the eurotiomycete A. otae. The consequences of this on Lbb pathogenicity (if any) are not known. One other intriguing example is that of NPS8, the five-module NPS thought to be involved in the production of the transiently produced depsipeptide, phomalide. Phomalide is postulated to be an important pathogenicity determinant as it has been proposed to act as an host-selective toxin (HST) [61]. The gene cluster is located in an AT-rich subtelomeric region of the genome of Lmb and has no known homologs.

For SSP-encoding genes, indication of HGT were sparse due to high level of sequence divergence with possible homologs within or outside the species complex. We confirmed here that effector genes did not belong to recognisable multigene families, and that TEs are unlikely to promote multiple duplications. This is consistent with the known impact of RIP on restriction of gene innovation mediated by duplications [11]. However, in cases where homologs could be identified, another impact of TEs on SSP genes could be evidenced here for an important part of the effector genes known to be also behaving as avirulence determinants during plant pathogen interaction. Microsynteny analyses between the members of the species complex highlighted the fact that, in the Lmb genome, 5 of 7 characterized avirulence genes present in AT-rich isochores have been translocated from another location in the genome to these TE-rich environments in the course of evolution. This is reminiscent at a different scale of what is observed in M. oryzae, where a paralog of Avr-Pita (Avr-Pita3) is found at an invariant genome location, while Avr-Pita and other variants may be absent or present at different chromosomal locations, or on different chromosomes, depending on the isolate [62]. In $M$. oryzae, both patterns of complete loss of the gene and patterns of multiple translocations were ascribed to the close association of Avr-Pita with a retrotransposon. The authors postulated that other avirulence genes of $M$. oryzae may have the same behaviour and also be subjected to multiple translocations in the genomes and that this maintains a pool of isolates with the avirulence gene when selection is exerted so that it can be easily disseminated in populations when the selection is no more present. In our study, these translocations were not identified between Lmb isolates but between members of a species complex displaying contrasted TE-content in their genome. This suggests that during the TE expansion, genes (known today as effector genes) were subjected to TE-mediated translocations, resulting in many cases in their isolation within highly dynamic TE-rich compartments. We thus highlight here another mechanism from what is reported in species for which TE are drivers of gene innovation via generation of multigene families: in Lmb, probably because of the activity of RIP, duplication only rarely occurs, but TEs contribute to displace the genes of importance in novel dynamic regions of the genome.

On this basis the question is to understand what can be the selective advantage of displacing effector genes in such plastic genomic regions and how this contributes to enhanced pathogenicity towards oilseed rape. While being morphologically very similar $[23,63]$ and adapted to crucifer hosts, the more divergent species of the species complex, Lmb, Lbb and Lbc have very similar host range and pathogenic behaviour. They are pathogenic towards Brassica species and share most of their infection strategies and specificity of life cycle $[64,65]$.

Also, the divergence time which predate speciation (ca. 22 MYA) between L. biglobosa and L. maculans correlates well with current estimates of the whole-genome triplication events that facilitated the origin of Brassica 
crops centered at 22.5 MYA [66]. This could indicate the L. maculans-L. biglobosa lineage co-evolved with its host to become adapted to these newly-born triplicated Brassica plants and that adaptation to Brassica predates enhanced pathogenicity towards oilseed rape observed in Lmb. Under this hypothesis, the very restricted host range of Lml (nonpathogenic to Brassica species but specialised on Lepidium sp. $[21,63]$ ) would be a secondary adaptation to a crucifer weed, possibly linked with its expanded repertoire of SSP-encoding genes compared to the other members of the species complex. In $M$. oryzae, effector repertoire is associated with host range expansion; loss of a single effector AVR-Co39 enables this fungus to colonize rice, as well as foxtail millet $[67,68]$. Perhaps the expanded repertoire of effectors in $\mathrm{Lml}$ contributes to its narrower host range and its specialisation to Lepidium sp. compared to other members of the species complex.

While pathogenic strategies and life cycle characteristics have been conserved between Lmb and Lbb/Lbc for 22 million years, Lmb shows some pathogenicity traits that may have been acquired more recently. Two main differences exist between the species: aspects of leaf lesions and ability to develop the stem canker. According to the leaf symptoms they cause in the field or in controlled environments, Lbb and Lbc often have been considered as "weakly pathogenic" [21,69]. However Lbb and Lbc often cause large lesions on cotyledons: Lmb causes grey tissue collapse with no visual evidence of plant responses, suggesting the fungus has deployed mechanisms to suppress plant defenses, while the L. biglobosa isolates cause limited tissue collapse containing numerous largesize black spots suggesting the presence of some plant defense responses [70,71] (Additional file 24: Figure S8). $\mathrm{Lmb}$ is the most damaging pathogen of B. napus as it causes cankers at the base of the stem that cause the plant to lodge, resulting in significant losses at harvesting, while Lbc and Lbb cause limited upper stem lesions, of much lesser incidence on yield. These differences in pathogenic abilities were difficult to relate to gene content since most of genes, which are species-specific and thus potentially involved in species-specific life traits mostly did not have any attributed function. In contrast, genes with possible function in disease (e.g. CAZys and proteases that are responsible for fungal nutrition) were conserved between the different members of the species complex. In addition, the amount of SSP-encoding genes was comparable between the three species. However, most of the speciesspecific effector genes of Lmb expressed early during the plant infection are closely associated with TEs in the Lmb genome and located in large AT-rich isochores. It is possible that the displacement in AT-isochores resulted in accelerated sequence diversification of effector genes due to action of RIP on non-duplicated sequences hosted in the AT-rich environment $[17,18]$.
The lower AT content of these genes compared to that of other genes encoding SSPs in the GC isochores of Lmb [9] or of genes encoding SSP in other members of the species complex (this study) would be in favor of such an environment-mediated accelerated rate of diversification of the genes and thus explain the enrichment in species-specific effector genes in AT-isochores of Lmb.

Our data also indicate a link between proximity of TEs and in planta gene expression. Eventually, moving effector genes in the AT isochores would favor in planta expression of effector genes and since $c a .120$ candidate effector genes are located in (or at the borders) of AT-isochores results in concerted expression of these at the onset of plant infection [9]. We previously showed that AT-isochores create heterochromatic landscapes responsible for an epigenetic control of the effector gene expression [72]. Here, we showed that patterns of expression of effector genes differ between Lmb and Lbb. Amongst the top 100 genes expressed following cotyledon at seven dpi, $45 \%$ encode SSPs in the Lmb genome, whereas this proportion decreases to 21\% for Lbb (Additional file 23: Supplementary Data 4). The finding that $30 \%$ of the top $100 \mathrm{Lmb}$ genes up regulated in planta represent species-specific genes located in AT-isochores, compared to very few in Lbb, suggests that the concerted expression of these speciesspecific SSPs in Lmb play a major role at the onset of the plant colonisation and may contribute to the development of the typical grayish-green tissue collapse on leaves, possibly by suppressing the plant PTI (Pathogen Triggered Immunity), a function commonly attributed to effector genes expressed in the earliest stages of plant infection [73]. The Lmb-Brassica co-evolution and the early expression of effector genes in planta to suppress PTI eventually allowed the plant to build a second line of defense response, Effector Triggered Immunity (ETI) that seems to occur in the Lmb-B. napus interaction, but not in the interaction with Lbb or Lbc [64]. As a consequence, genefor-gene interactions are observed in the Lmb-Brassica interactions, but not in interactions of Brassica species with L. biglobosa species. In contrast to the Lmb case, the dark lesions caused by Lbb or Lbc ([71]; Additional file 24: Figure S8) suggest that the plant initiates PTI and that the fungus cannot efficiently suppress it. In this case, speed of growth of the fungus and multiple re-infection points nevertheless allow more or less efficient subsequent tissue colonisation.

Apart from an extensively described role of AT-isochores in rapid adaptation to plant resistance selection $[16,18,19]$, and probable role of HGT, TEs thus are likely to have played a major role in the course of evolution by moving effector genes to novel plastic genomes environments promoting sequence diversification and concerted expression of effector genes at the onset of plant infection, eventually 
resulting in the success of Lmb as a destructive pathogen of oilseed rape and other Brassicas.

\section{Conclusion}

In fungi, genome invasion by TEs is often postulated to have contributed to the success of phytopathogens, mutualists and endophytes and, as stated by Raffaele \& Kamoun [8], phytopathogens often have expanded genomes compared to their free-living relatives. The $L$. maculans-L. biglobosa system also shows that TEs have contributed to intrachromosomal inversions, likely resulting in speciation as already described for more complex Eukaryotes. In Lmb, as in other phytopathogens, the hosting of effector genes in TE-rich genome environment contributed to sequence diversification and probably adaptation to new hosts or better adaptation to the existing host. It currently contributes to a highly dynamic plasticity and diversification of these genes. In Lmb, RIP mutation increases the speed with which the detrimental genes can be mutated to extinction, rendering migration of low importance compared to the ability to generate variants locally in a single sexual cycle. Todate, this process has not been documented in other fungal species. The hosting of effector genes in such dynamic genome environments has a dual advantage for phytopathogens: immediate adaptation to a new source of resistance (provided the effector gene is dispensable) consistent with the speed of birth and dissemination of new virulent populations, and long-term enhanced ability to duplicate and diversify effector genes to facilitate adaptation to the host or adaptation to new hosts. Recent advances suggested that the association of effector genes with TEs also has an impact on epigenetic, heterochromatinbased regulation of their expression. This, along with evolutionary consequences of this finding, provide a new and promising field for research.

\section{Methods}

Biological material

Isolates IBCN84 ( $L$. maculans 'lepidii') and IBCN65 (L. biglobosa 'thlaspii') are part of the International Blackleg of Crucifer Network collection maintained at INRA-Grignon and AAFC Saskatoon, Canada. Both isolates were obtained as hyphal tip-purified isolates in Saskatchewan either from stinkweed (Thlaspi arvense) (IBCN65) or from peppergrass (Lepidium sp.) (IBCN84) [21]. Isolate B3.5 (L. biglobosa 'brassicae') is one of two isolates that were used to formally establish the new $L$. biglobosa species name [30]. It was obtained as a singleascospore isolate ejected from a pseudothecia formed on Brassica juncea cv. Picra in an experimental field at INRA-Le Rheu [30]. The L. biglobosa 'canadensis' isolate 06VTJ154 (hereafter named J154) was cultured from ascospores released from sexual fruiting bodies on $B$. juncea stubble collected from Burren Junction, New South Wales, Australia as described by Van de Wouw et al. [70]. The L. maculans 'brassicae' isolate WA74 was purified from infected stubble of oilseed rape collected from Western Australia. It is also known as IBCN76 [21]. The Lmb isolate used for RNA-seq experiments was IBCN18, an Australian isolate cultured from infected stubble of oilseed rape.

\section{Sequencing and assembly}

For isolates IBCN84 (L. maculans 'lepidii'), IBCN65 (L. biglobosa 'thlaspii') and B3.5 (L. biglobosa 'brassicae'), a Paired-End $8 \mathrm{~Kb}$ library was constructed according to the protocol 454. A run and a half was done on the Titanium version, generating 580, 511 and $614 \mathrm{Mb}$ of raw data, respectively. An additional Paired-End 20-kb library was built for isolate B3.5. An additional run was done on the Titanium version, generating $380 \mathrm{Mb}$ of raw data. Additional libraries were constructed according to the Illumina protocol with an average size of $250 \mathrm{bp}$ inserts for IBCN84 and IBCN65 and 350 bp for B3.5. Libraries were sequenced on three lanes (for IBCN84 and B3.5) and 2 lanes for IBCN65 on a GAIIx, 76 bp in single sequencing, generating $7.8 \mathrm{~Gb}$ of raw data for IBCN84, $6.08 \mathrm{~Gb}$ for B3.5 and $4.9 \mathrm{~Gb}$ for IBCN65. The Titanium sequences were assembled by Newbler and the sequences of the scaffolds were corrected using the Illumina sequences.

For isolate WA74, DNA was extracted (CTAB extraction protocol) from mycelia grown on V8 agar plates. Sequencing was done using Roche 454 Titanium platform both for shotgun sequencing and sequencing of an $8 \mathrm{~kb}$ mate-paired library. A total of 1,308,735 shotgun reads was obtained including 459,965 reads from the paired library prep where 248,433 were discernable pairs and had an average insert size of $7.5 \mathrm{~kb}$. A de novo assembly of isolate WA74 was performed for the shotgun and paired library data using gsAssembler version 2.3 (Roche/454).

L. biglobosa 'canadensis' isolate J154 was grown in 10\% Campbell's V8 juice for five days and genomic DNA was extracted from mycelia and sequenced by the Australian Genome Research Facility, Melbourne, Australia using Illumina HiSeq2000. Libraries were constructed with a 250 bp insert size. A single lane of 100 bp pair-end sequencing was used to generate $32 \mathrm{~Gb}$ of raw data. Reads were trimmed to a minimum quality of phred 28 using FastX-toolkit software, producing 310 million trimmed reads. Trimmed reads were assembled de novo using the Velvet short read assembler v1.1.06 [74] with the Velvet Optimiser Perl script to select the k-mer (49), expected coverage (402) and coverage cutoff (43) values. The final assembly of L. biglobosa 'canadensis' J154 produced $29.48 \mathrm{Mb}$ of scaffolds $>200 \mathrm{bp}$. 


\section{Optical mapping of the v23.1.3 genome}

The optical map of Leptospheria maculans 'brassicae' v23.1.3 was generated using the Argus Whole-Genome Mapping System (www.opgen.com). Restriction enzyme, MluI, was chosen using Enzyme Chooser (OpGen Inc., Gaithersburg, MD), which identifies enzymes that result in a 6-12 kb average fragment size and no single restriction fragment larger than $80 \mathrm{~kb}$ across the genome. Overall, 8915 single-molecule restriction maps with an average size of $248 \mathrm{~kb}$ were generated. The total size was $\sim 2 \mathrm{~Gb}$ and 75 supercontigs were obtained after assembly. Fasta files were imported to the MapSolver software and converted into in silico maps by analysis of MluI restriction fragments. The MapSolver software then compared and reconciliated the different restriction maps.

\section{Bioinformatics}

\section{Gene annotation}

The automated gene annotation was carried out using a combination of two $a b$ initio gene predictors, Fgenesh [75] and Genemark [76]. Fgenesh has been previously used as a part of the EuGene pipeline [77] for annotation of the L. maculans 'brassicae' v23.1.3 genome [9]. Genemark was trained on the twenty largest SuperContigs of L. maculans 'brassicae' v23.1.3 with the repeated sequences masked using RepeatMasker [78] in order to avoid the RIP bias in base usage on the repeated elements. Both Fgenesh and Genemark were firstly benchmarked on one SC of v23.1.3 and showed that Genemark gene models were better defined than Fgenesh and EuGene gene models. As a consequence, Genemark predictions were always prioritized over Fgenesh prediction in case of inconsistent annotation between the two predictors. Both Fgenesh and Genemark were run on repeatmasked genomic sequences and the results were combined. Gene models encoding proteins $>30$ amino acids were compared and a decision made as follows: (i) if a similar gene model was predicted at the same locus, or if it was predicted by one or the other of the predictors, this gene model was kept; (ii) if two different gene models were predicted at the same locus, the Genemark prediction was prioritized; (iii) if a predicted gene model corresponded to two or more gene models from the other predictor, the latter was kept. All validated genes were then translated into proteins and their features were written in a GFF3 formatted file which was used for visualisation (e.g. with Artemis [79]).

\section{Functional annotation}

Automated functional annotation of the predicted proteins was performed by using a combination of BLAST [80] and InterProScan [81]. First, each protein was compared by BLASTp to the NR database, and only the hit results matching the following criteria were kept for further analysis: (i) the e-value should be less than 1e-06, (ii) the similarity percentage should be over $30 \%$, (iii) at least $70 \%$ of the query sequence should be covered by the alignment length, (iv) the subject (hit) sequence length should represent between 75 and $125 \%$ of the query sequence length. Then, all validated results were pooled and average values were calculated for each of the above-mentioned criteria. A consensus description was then obtained by text-mining. According to these different features, proteins were divided into three classes: (i) proteins with no BLAST hit result or BLAST hit results with a mean percentage of similarity lesser than $40 \%$, a mean percentage of coverage of the query sequence length by the alignment length lesser than $80 \%$ and a mean percentage of coverage of the query sequence length by the subjects length lesser than $85 \%$ or greater than $115 \%$, and (ii) proteins with no protein domain identified by InterProScan. This class is classified as «predicted protein », i.e., predictions with no functional support. It usually contained species-specific sequence with no known domains. The second class, termed " hypothetical proteins », included predictions that (i) had at least one domain identified by InterProScan in the InterPro database [82] and fulfill the abovementioned BLAST result criteria but for which text mining indicated «hypothetical protein » in more than $90 \%$ of the hits, or (ii) fulfill the BLAST results conditions with a consensus description corresponding to a function but with no protein domain identified, or (iii) with no BLAST results but with at least one domain identified from the InterPro database. Globally, this class contained predictions with slight functional support that might correspond to conserved proteins among several organisms but with no defined functions, or to splitted/ merged predictions. The third class included predictions that fulfill the BLAST result conditions, with at least one domain from the InterPro database and with consensus hit description corroborated by the protein domains identified with InterProScan. This class was termed the " similar to function » protein and included well conserved proteins with defined functions among several organisms. All parameter values used in this section were optimized values based on comparison between results of automated in silico and « manual » in silico functional annotation.

\section{Identification and annotation of genes encoding SSPs and secondary metabolite biosynthetic genes}

A protein was classified as a SSP (i) if a signal peptide was predicted by both Neural-Network and Hidden Markov Model methods of SignalP 3.0 [83], (ii) if TargetP 1.1 [84] predicted the protein being in the secretion pathway, (iii) if TMHMM 2.0 [85] detected none or one transmembrane domain if this latter is at least at 30\% included in the signal peptide, (iv) and if its length was $\leq 300$ amino 
acids. SSP were identified by merging of two sets of predicted proteins. The first set resulted from a step of gene annotation as described above. After this step, the validated gene models were masked on the genomic sequences and another round of gene annotation was carried out. From this second gene model set, the ones encoding SSPs were then analysed.

Genes encoding key enzymes in fungal secondary metabolism were sought. Non-ribosomal peptide synthases (NRPS) and polyketide synthase (PKS) were identified by searching both the predicted proteins and genome assemblies of each species with previously characterised NPS and PKS proteins from Lmb v23.1.3 [9]. Both BLASTp and tBLASTn algorithms were used. Any match with greater than $35 \%$ sequence similarity to the previously identified proteins was compared by BLAST against the NCBI database to detect indicative domains, as well as best matches in other species.

\section{Analysis of gene conservation}

The 57,964 proteins predicted in the Leptosphaeria species complex were grouped using orthoMCL (with default parameters). OrthoMCL created 10,916 families that contained 48,013 sequences. In order to obtain 1:1 orthologous relationships between the sequences, families made of proteins from only one taxon or containing a number of protein larger than that of taxa, were excluded. After this screening step, 10,131 families containing 43,437 sequences $(74.9 \%$ of the species complex proteome) remained.

The presence of proteins that were not included within the 10,131 families, was investigated in genomes of the other members of the species complex using different programs of BLAST with an e-value cut-off of $1 \mathrm{e}^{-5}$ and a request for Best Hits only: (i) BLASTn; (ii) tBLASTn on the 6 frame-translated genome sequences; (iii) BLASTp on the ungrouped proteins of the other members. All BLAST hits with coverage lower than 50\% of the query sequence were considered as negative. According to the different combination of results, each protein was classified as: (i) species-specific, i.e. sequences that were not detected at the nucleotide level in the other assemblies or were pseudogenized; (ii) specific of a few members of the species complex, i.e. present in at least another member of the species complex, which can or not correspond to non-predicted genes in the other assemblies; (iii) unresolved, corresponding to sequences for we could not decide presence or absence status. Pseudogenes were hypothetized to occur when BLASTn and tBLASTn, but not BLASTp, provided significant results on other predicted proteins. To ascertain the reality of pseudogenes, the tBLASTn alignment was analyzed and the subject sequence was investigated for occurrence of stop codons or mutations in the start codon.

\section{Annotation of transposable elements}

Transposable Elements were identified and annotated using the REPET pipeline [86]. The TEdenovo pipeline detects repeat copies, clusters them into families and generates a consensus sequence for each family. Then these sequences are classified (TEclassifier.py) using tBLASTx and BLASTx against the Repbase Update database [87] and by identification of structural features such as long terminal repeats (LTRs) or terminal inverted repeats (TIRs), but due to the difficulties for Newbler to assemble correctly repeated regions, the majority of the consensus were not categorized into known TE families $[88,89]$. Thus, manual annotation was necessary. Consensus sequences were clustered based on homologies research by BLAST, then aligned with ClustalX2 [90] and a new consensus was created. These steps were repeated until there were no more alignments by BLAST between the sequences, then consensuses were submitted to TEclassifier. py from the TEdenovo pipeline. The sequences were also translated into the six frames using Transeq from the EMBOSS package [91] in order to carry out a protein domain research on the Conserved Domain Database (CDD) [92] using RPS-BLAST. TE families of each strain were classified and named according to Wicker et al. [88]. These families constitute the TE repertoire of the L. maculans L. biglobosa species complex which was used afterwards to reannotate each genome of the complex and to retrieve similar sequences among genomes of other Ascomycete species, mined on the JGI MycoCosm portal (http://genome.jgi.doe.gov/programs/fungi/index.jsf). For this latter purpose, the most GC-rich copies (i.e. the ones with the least degrees of RIP mutation) of the different TE families were used to search for homologous sequences in the Ascomycota. RIP analysis was performed automatically on multiple alignment of sequences of each TE family using the RIPCAL software [93].

\section{Setting up the synteny browser}

A GBrowse-based synteny browser, GBrowse-syn [94], was set up to display the synteny between genomes of the Leptosphaeria complex. Genome assemblies were aligned with Mercator and MAVID softwares [95]. Using Blat, Mercator aligned the CDS of all assemblies, providing constraints for genomic alignments with MAVID. For the L. maculans isolates, Mercator identified at least $94 \%$ of CDS as anchors for alignments (Lmb v23.1.3: 95\%, Lmb WA74: 95\%, Lml IBCN84: 94.3\%), while it was lowered to $88 \%$ for L. biglobosa isolates (Lbt IBCN65: 89.5\%, Lbb B3.5: 87.3\%). The Lbc isolate was not included due to extensive genome fragmentation. Where the number of aligned CDS was consistent for L. maculans isolates, the orthology map inferred from anchors revealed that the orthologous segments covered $64 \%$ and $66 \%$ of WA74 and v23.1.3 genomes, respectively. This seemingly low 
coverage is due to the importance of repeated region in the genomes of Lmb isolates. The other genomes were covered at $86.5 \%, 89.5 \%$ and $87.3 \%$ for IBCN84, IBCN65 and B3.5, respectively. Genomic alignments were performed with MAVID and loaded with genome annotations in MySQL databases. GBrowse-syn was configured to display the blocks of synteny (http://urgi.versailles.inra.fr/ gb2/gbrowse_syn/leptosphaeria_synteny/).

\section{Phylogeny and estimates of divergence time}

An aggregative hierarchical clustering procedure was performed on all versus all BLASTp results from protein sequences of 80 annotated genomes at NCBI (Additional file 25: Table S13). This procedure is similar to that used to generate clusters in the Entrez Protein Clusters database at NCBI (ProtClustDB). The following filters were applied: cluster members were required to have compositional BLAST hits covering at least $70 \%$ of each protein length and a pairwise score between cluster members was required to be at least $20 \%$ of the largest of the self-scores. Clusters were selected that contained one protein per taxon with at least 75 taxa present. This represented a broad sampling of Ascomycota, Basidiomycota and Chytridiomycota orthologs. Protein sequences from these clusters were subsequently used as queries in BLASTp searches in order to extract orthologs from annotated dothideomycetes genomes at JGI (http://genome.jgi.doe.gov/programs/fungi/index.jsf; Additional file 26: Table S14) and those generated for this study. Individual protein alignments were used to generate phylogenetic trees in FastTree [96]. The phylogenies were then manually inspected for contradictory placement of taxa resulting from paralogs, or poor annotations. Taxa were judged to be contradictory when their placement above order level, in $70 \%$ bootstrap resamplings, contradicted accepted phylogenetic placements from recent broad analyses [25,27]. The first selection of single copy clusters yielded 28 candidates. After examining the phylogenetic placements a further set of 9 proteins were removed. This series of selections yielded a final set of 19 aligned proteins. These alignments were then edited with Gblocks v.0.91b [97] with the following parameters $\mathrm{b} 3=8 \mathrm{~b} 4=5 \mathrm{~b} 5=\mathrm{h}$. The final concatenated alignment consisted of the following 19 proteins: Cct3p, Chc1p, Frs2p, Hsp60p, Imp3p, Kre33p, Lys1p, Pol3p, Pro2p, Pup1p, Ret1p, Rpo21p, Rpt2p, Rpt5p, Rrb1p, Rvb1p, Rvb2p, Sec26p and Tcp1p (following Saccharomyces cerevisiae nomenclature). The fungal taxa were trimmed to 51 in order to allow a relatively small and focused data set for analysis. This resulted in a data matrix of 11694 amino acids (aa) with $3.31 \%$ consisting of gaps and completely undetermined characters.

The data set was analysed using Bayesian relaxed molecular clock approaches in BEAST v1.7.3. An xml file was prepared with the aid of BEAUTi v.1.7.3 [98]. This included a starting tree generated in RAxML version 7.3.1 and calibrated with r8s [99]. The tree as well as details on tree analysis were deposited with the protein alignments used at TreeBASE (submission ID 15756). The same phylogeny was also used to determine which nodes could be constrained. Bayesian relaxed uncorrelated lognormal clock analyses with a birth-death tree prior were specified under the WAG substitution model (Gamma + invariant sites). Secondary time calibrations were used from recent publications: a normal distributed prior of 662 MYA was set for the root of the tree with uniform prior minimums of 417 MYA and 402 MYA for Ascomycota and Basidiomycota respectively following [100]. Maximum dates were set to 644 and 664. Similar restrictions were placed on Dothideomycetes with a minimum age of 284 and a maximum of 394 following Gueidan et al. [101]. Five independent BEAST MCMC chains were run for 15 million generations sampling data every 1000th generation using the XSEDE computing infrastructure through the CIPRES Science Gateway webportal [102]. The resulting log files were combined using LogCombiner v1.7.3 and inspected with Tracer v1.5 to confirm the estimated sample sizes. The runs converged to stable likelihood values independently and the first 1500 trees were discarded. The remaining 13500 ultrametric trees from each run were combined and analyzed using TreeAnnotator v1.7.3 to estimate the $95 \%$ highest posterior densities (HPD). The consensus chronogram including the 95\% HPD and the mean age estimates were visualised in Figtree v1.3.1 and certain clades were collapsed for clarity in Figure 1. The full figure is available as Additional file 2: Figure S2.

\section{Gene expression data}

Expression data based on oligoarrays for isolate Lmb v.23.1.3 previously obtained [9] and deposited in the gene Expression Omnibus under accession code GSE27152 were used. In addition, whole-genome expression arrays of Lbb isolate B3.5 were obtained and analysed. They were manufactured by NimbleGen Systems Limited (Madison, WI) and contained five independent, non-identical, 60mer probes per gene model. A total of 12,457 gene models were analysed with 2,008 random 60-mer as well as control probes and labelling controls. Total RNA was extracted from mycelium grown during one week in Fries liquid medium and from oilseed rape leaves after 3, 7 and 14 days post-infection using TRIzol reagent (Invitrogen) according to the manufacturer's protocol. Total RNA was treated with DNase I RNase-Free (New England Biolabs). Total RNA preparations (three biological replicates for each sample) were amplified by PartnerChip (Evry, France) using the SMART PCR cDNA Synthesis Kit (Invitrogen) according to the manufacturer's instructions. Single dye labeling of samples, hybridization procedures, 
data acquisition, background correction and normalisation were performed at the PartnerChip facilities following the standard protocol defined by NimbleGen [103,104]. Average expression levels were calculated for each gene from the independent probes on the array and were further analyzed. Gene-normalized data were subjected to Analysis of NimbleGen Array Interface Suite [105]. ANAIS performs an ANOVA test on log-10 transformed data to identify statistically differentially expressed genes. This test uses the observed variance of gene measurements across the three replicated experiments. To deal with multiple testings, the ANOVA $p$ values are further subjected to the Bonferroni correction. Transcripts with a $p$ value lower than 0.05 and more than 1.5 -fold change in transcript level were considered as significantly differentially expressed during in planta conditions (3, 7 or 14 dpi) compared to mycelium growth. To estimate the signal-to-noise threshold (signal background), ANAIS calculates the median of the intensity of all of the random probes present on the oligoarray, and provides adjustable cut-off levels relative to that value. Gene models with an expression higher than three-times the median of random probe intensities in at least two of three biological replicates were considered as transcribed.

In parallel, RNAseq analyses were performed on another Lmb isolate and on Lbc. Mycelia of Lmb IBCN18 and of Lbc J154 were harvested on Miracloth after 7 days growth in oilseed rape liquid medium. Infected cotyledonary tissue $(0.5 \mathrm{~mm}$ diameter) was harvested from 32 B. napus $\mathrm{cv}$. Westar seedlings 7 days post inoculation (dpi) [106]. RNA was extracted using Trizol reagent (Life technologies) and subsequently DNaseI-treated (Promega). Two biological replicates of RNA, with an RNA integrity number $(\mathrm{RIN})>6$, were sequenced with Illumina TruSeq version 3 chemistry on an Illumina HiSeq2000 sequencer at the Australian Genome Research Facility (AGRF). In vitro derived RNA was sequenced with 100 bp paired-end reads in order to aid gene annotation, while in planta derived RNA was sequenced with 100 bp single-end reads. A total of $15.5 \mathrm{~Gb}$ sequence was generated from two in vitro libraries (7.75 Gb per sample), and $72 \mathrm{~Gb}$ sequence was generated from 12 in planta libraries (6 Gb per sample). Reads were trimmed to a minimum phred score of 20 using Nesoni sequence software and remaining Illumina Tru-seq adaptor sequences were removed. Trimmed reads were aligned to reference genome sequences with Tophat v1.4.1 splice-junction mapper [107]. Reference genomes were L. maculans 'brassicae' v23.1.3 [9] L. biglobosa 'canadensis' isolate J154 (this study). Aligned reads were quantified using Cufflinks v1.0.3 transcript assembly and quantification software [108].

Gene models for Lbc isolate J154 were validated with the RNA-seq sequence data. Of the 11068 gene models, 8521 had $>10 x$ coverage, 9979 had $>1 x$ coverage and
530 did not have a detectable transcript. Of the 11068 gene models, 8948 had a FPKM (fragments per kb of exon per million mapped reads) value $>1$; this value is an indication of significant expression.

\section{Effect of proximity of repetitive sequences on in planta expression of genes}

A total of 7561 orthologous pairs between isolates Lmb IBCN18 and Lbc J154 were identified and RNA-seq gene expression values (FPKM) for each gene in two conditions, in planta (infected B. napus cv Westar at $7 \mathrm{dpi}$ ), and in vitro (oilseed rape medium at $7 \mathrm{dpi}$ ) were determined. Genes with undetectable expression (no assignable FPKM) were excluded, leaving 7415 ortholog pairs. Quantile Normalisation was applied to the four gene expression datasets so that they could be directly compared. The repeat category for each ortholog pair was determined: the RepeatMasker output based on TE families described above defined the repeat content of each genome, and all repetitive sequences were included in the analysis. For each gene considered, either another gene or a repetitive sequence was adjacent; if a gene was adjacent to the end of a scaffold, it was categorised as "repetitive sequence adjacent". This led to 16 categories based on the presence/absence of a repetitive sequence adjacent to promoter and terminator for orthologs in Lmb and Lbc. However, four categories based on the promoter region were analysed. An expression ratio was calculated from the log2 (in planta expression /in vitro expression) for each gene. A positive value means the gene is more highly expressed in planta; a negative value means the gene is more highly expressed in vitro culture.

\section{Ethics}

Not applicable; this research is essentially a bioinformaticsbased one and did not involve research on human, animals or plants.

\section{Availability of supporting data}

Tree and alignment have been submitted to TreeBase as matrix S15756. They are available at http://purl.org/phylo/ treebase/phylows/study/TB2:S15756.

Leptosphaeria biglobosa 'canadensis' genome information and RNAseq data have been deposited to genbank linked to NCBI Bioproject ID "PRJNA230885".

Assembly for all other genomes have been deposited to EBI under accession numbers FO905058 FO907085.

Sequences of Transposable Elements of the species complex are downloadable from https://urgi.versailles.inra.fr/ Species/Leptosphaeria/Sequences-Databases/Download. 


\section{Additional files}

Additional file 1: Figure S1. Representative electrokaryotypes and presence of transposable elements in the genomes of isolates of the $L$. maculans-L. biglobosa species complex. (a) Electrokaryotypes were separated by Contour-clamped Homogeneous Electric Field (CHEF) electrophoresis. (b) Southern blotting using one probe derived from the retrotransposon RLG_Rolly. Identity of the isolates is as follows $L$. maculans 'brassicae': lane 1, v23.1.3; lane 2, v29; lane 3, IBCN18; L. maculans 'lepidii': lane 4, IBCN84; lane 5, Lepi-1; lane 6, Lepi-2; L. biglobosa 'brassicae': lane 7, IBCN10; lane 8, IBCN93; L. biglobosa 'canadensis': lane 9, IBCN62; lane 10, IBCN82; L. biglobosa 'australensis': lane 12, IBCN30; lane 13, IBCN91; L. biglobosa 'thlaspii': lane 13, IBCN65; lane 14, IBCN64; lane 15, molecular weight marker $H$. wingei chromosomes. Names of isolates in bold are those sequenced here or the reference isolate previously sequenced [9].

Additional file 2: Figure S2. Expanded chronogram of major classes in Ascomycota, with a focus on Dothideomycetes, produced with BEAST from a data set of 19 truncated proteins. Numbers at nodes indicate mean node ages in millions of years and light green bars indicate their 95\% highest posterior density intervals. A broken line indicates uncertain phylogenetic placement.

Additional file 3: Figure S5. Genomic DNA of isolates of Leptosphaeria species digested with restriction enzymes BamHI (RLC_Pholy) or HindllI (RLG_Rolly) and hybridised with probes of transposable elements abundant in L. maculans 'brassicae'. (a, b) Probed with RLG_Rolly; RLC_Pholy, respectively. (c, d) Ethidium bromide stained gel of $(a, b)$, respectively. None of the probes hybridised to DNA of L. biglobosa 'canadensis' or with another Australian member of the species complex (not included in the present study), L. biglobosa 'occiaustraliensis'.

Additional file 4: Table S1. Characteristics of selected genomes of Dothideomycetes

Additional file 5: Table S2. Gene model statistics for the Leptosphaeria spp. genomes.

Additional file 6: Table S3. Chromosomal assignment and correspondance between L. maculans 'brassicae' and L. maculans 'lepidii'.

Additional file 7: Figure $\mathbf{5 3}$. Whole genome DNA comparison of Leptosphaeria maculans 'brassicae' isolate v23.1.3 to progressively more distantly related members of the species complex. (a) comparison between two Leptosphaeria maculans 'brassicae' isolates, v23.1.3 and WA74 showing lack of detectable chromosomal reorganisations; (b) comparison with L. maculans 'lepidii' showing extensive macrosynteny with only limited number of intrachromosomal inversions; (c) comparison to Leptosphaeria biglobosa 'brassicae' and (d) comparison to Leptosphaeria biglobosa 'thlaspii' showing many intrachromosomal inversions but no detectable large scale translocations.

Additional file 8: Figure S6. Circos representation of chromosome-bychromosome genome conservation between L. maculans 'brassicae' (right part of the diagramme) and L. maculans 'lepidii' (left part). For L. maculans 'brassicae', each chromosome is represented in a different colour and black blocks within coloured bars represent AT-rich genome blocks enriched in transposable elements.

Additional file 9: Table S4. Location and distance from TEs of the 30 intrachromosomal inversions in the chromosomes of L. maculans 'brassicae'.

Additional file 10: Table S5. Characteristics of Class I

(Retrotransposons) Transposable Elements identified in the Leptosphaeria maculans-L. biglobosa species complex.

Additional file 11: Table S6. Characteristics of Class II (DNA transposons) Transposable Elements identified in the Leptosphaeria maculans-L. biglobosa species complex.

Additional file 12: Supplementary Data 1. Unclassified repeated elements and their occurrence in species of the L. maculans-L. biglobosa species complex.

Additional file 13: Supplementary Data 2. Occurrence and conservation of annotated families of transposable elements in the Pleosporales.
Additional file 14: Figure S4. Transposable Elements dynamics in the Dothideomycetes lineage. Red stars indicate species genomes in which TE sequences identified in the L. maculans-L. biglobosa species complex are present.

Additional file 15: Table S7. Insertion polymorphism of Transposable Elements between the two isolates of L. maculans 'brassicae'. (XLS 9 kb).

Additional file 16: Table S8. Predicted gene conservation between the genomes of isolates of the Leptosphaeria maculans-Leptosphaeria biglobosa species complex.

Additional file 17: Figure S7. Conservation of cysteine spacing in a series of orthologs of avirulence proteins of L. maculans 'brassicae'. (a) multiple alignment of orthologs of AvrLm4-7, (b) multiple alignment of orthologs of AvrLm6.

Additional file 18: Table S9. Conservation of genes encoding avirulence effector in members of the L. maculans-L. biglobosa species complex and other fungal species.

Additional file 19: Table S10. Non-Ribosomal Peptide Synthases (NPS) genes of the L. maculans-L. biglobosa species complex.

Additional file 20: Supplementary Data 3. Top 10 Blast hit for the secondary metabolite genes (PKS and NPS) found in members of the L. maculans-L. biglobosa species complex.

Additional file 21: Table S11. Polyketide Synthases (PKS) genes of the L. maculans-L. biglobosa species complex

Additional file 22: Table S12. The PKS21 gene cluster of Leptosphaeria biglobosa 'brassicae' and homologs in the dermatophyte Arthroderma otae.

Additional file 23: Supplementary Data 4. Top 100 genes overexpressed at 7dpi in species adapted to oilseed rape, Lmb, Lbb and Lbc.

Additional file 24: Figure S8. Typical symptoms caused by Leptosphaeria maculans (a) and Leptosphaeria biglobosa (b) on cotyledons of oilseed rape following infection in controlled environment. In (a) two different isolates were inoculated, one causing the typical susceptibility symptom (left) and one expressing an avirulence effector recognised by the Effector Triggered Immunity plant machinery (right) resulting in a typical hypersensistive response to infection. In (b), susceptibility symptoms differ from that in (a) by the occurrence of numerous dark necrotic spots and development of chlorosis never observed in (a).

Additional file 25: Table S13. List of taxa which predicted protein annotation (available in 2012) were used in hierarchical clustering procedure.

Additional file 26: Table S14. List of dothideomycetes taxa with annotated genomes (available in 2012) from which orthologs were identified.

\section{Competing interests}

The authors declare that they have no competing interests.

\section{Author contributions}

Conceived and designed the experiments: JG, RGTL, JLS, CLS, NL, MGL, CC, BJH, MHB, TR. Performed the experiments: JG, RGTL, JLS, CLS, APVdW, IF, BR, $\mathrm{NL}, \mathrm{MGL}, \mathrm{BO}, J \mathrm{~J}, \mathrm{VB}, \mathrm{SM}, \mathrm{MHB}$. Analyzed the data: JG, RGTL, JLS, CLS, BR, MGL, $J L, V B, S M, H B, B J H, M H B$, TR. Wrote the paper: JG, RGTL, JLS, CLS, BJH, MHB, TR. All authors read and approved the final manuscript.

\section{Acknowledgments}

This work was funded by the French agency Agence Nationale de la Recherche (ANR), contract ANR-09-GENM-028 ('Funglsochores') and by the French Technical Institute for oil crops, CETIOM. CLS acknowledges the Intramural Research Program of the NIH, National Library of Medicine. We thank Joelle Amselem and Jonathan Kreplak (INRA URGI, Versailles) for their help on genome annotation, and also Sébastien Duplessis (INRA/Université de Lorraine, Champenoux, France), and Eva Stukenbrock (MPI Marburg, Germany) for fruitful discussions. 


\section{Author details}

${ }^{1}$ INRA-Bioger, UR1290, Avenue Lucien Brétignières, BP 01, 78850 Thiverval-Grignon, France. ${ }^{2}$ School of Botany, The University of Melbourne, Melbourne, Victoria 3010, Australia. ${ }^{3} \mathrm{NIH} / \mathrm{NLM} / \mathrm{NCBI}, 45$ Center Drive, MSC 6510, Bethesda, Maryland 20892-6510, USA. ${ }^{4}$ INRA-Bioger, URGI Route de St Cyr, 78026 Versailles Cedex, France. ${ }^{5}$ Agriculture and Agri-Food Canada/ Agriculture et Agroalimentaire Canada, Saskatoon Research Centre, 107 Science Place, Saskatoon, SK, S7N OX2, Canada. 'Department of Computer, University of Saskatchewan, 110 Science Place, Saskatoon, SK, S7N 5C9, Canada. ${ }^{7}$ GENOSCOPE, Centre National de Séquençage, Institut de Génomique CEA/DSV, 2, rue Gaston Crémieux, CP 5706, 91057 Evry Cedex, France.

Received: 29 March 2014 Accepted: 26 September 2014

Published: 12 October 2014

\section{References}

1. Kupferschmidt K: Mycology. Attack of the clones. Science 2012, 337:636-638.

2. Goffeau A, Barrell BG, Bussey H, Davis RW, Dujon B, Feldmann H, Galibert F, Hoheisel JD, Jacq C, Johnston M, Louis EJ, Mewes HW, Murakami Y, Philippsen P, Tettelin H, Oliver SG: Life with 6000 genes. Science 1996, 274:563-567.

3. Galagan JE, Calvo SE, Borkovich KA, Selker EU, Read ND, Jaffe D, FitzHugh W, Ma L, Smirnov S, Purcell S, Rehman B, Elkins T, Engels R, Wang S, Nielsen CB, Butler J, Endrizzi M, Qui D, lanakiev P, Bell-Pedersen D, Nelson MA, Werner-Washburne M, Selitrennikoff CP, Kinsey JA, Braun EL, Zelter A, Schulte U, Kothe GO, Jedd G, Mewes W, et al: The genome sequence of the filamentous fungus Neurospora crassa. Nature 2003, 422:859-868.

4. Dean RA, Talbot NJ, Ebbole DJ, Farman ML, Mitchell TK, Orbach MJ, Thon M, Kulkarni $\mathrm{R}$, Xu JR, Pan H, Read ND, Lee YH, Carbone I, Brown D, Oh YY, Donofrio N, Jeong JS, Soanes DM, Djonovic S, Kolomiets E, Rehmeyer C, Li W, Harding M, Kim S, Lebrun MH, Bohnert H, Coughlan S, Butler J, Calvo S, Ma $L$, et al: The genome sequence of the rice blast fungus Magnaporthe grisea. Nature 2005, 434:980-986.

5. Kämper J, Kahmann R, Bölker M, Ma LJ, Brefort T, Saville BJ, Banuett F, Kronstad JW, Gold SE, Müller O, Perlin MH, Wösten HAB, de Vries R, Ruiz-Herrera J, Reynaga-Peña CG, Snetselaar K, McCann M, Pérez-Martín J, Feldbrügge M, Basse CW, Steinberg G, Ibeas Jl, Holloman W, Guzman P, Farman M, Stajich JE, Sentandreu R, González-Prieto JM, Kennell JC, Molina L, et al: Insights from the genome of the biotrophic fungal plant pathogen Ustilago maydis. Nature 2006, 444:97-101.

6. Cuomo CA, Güldener U, Xu JR, Trail F, Turgeon BG, Di Pietro A, Walton JD, Ma LJ, Baker SE, Rep M, Adam G, Antoniw J, Baldwin T, Calvo S, Chang YL, Decaprio D, Gale LR, Gnerre S, Goswami RS, Hammond-Kosack K, Harris LJ, Hilburn K, Kennell JC, Kroken S, Magnuson JK, Mannhaupt G, Mauceli E, Mewes HW, Mitterbauer R, Muehlbauer $\mathrm{G}$, et al: The Fusarium graminearum genome reveals a link between localized polymorphism and pathogen specialization. Science 2007, 317:1400-1402

7. Hane JK, Lowe RG, Solomon PS, Tan KC, Schoch CL, Spatafora JW, Crous PW, Kodira C, Birren BW, Galagan JE, Torriani SF, McDonald BA, Oliver RP: Dothideomycete-plant Interactions illuminated by genome sequencing and EST analysis of the wheat pathogen Stagonospora nodorum. Plant Cell 2007, 19:3347-3368.

8. Raffaele S, Kamoun S: Genome evolution in filamentous plant pathogens: why bigger can be better. Nat Rev Microbio/ 2012, 10:417-430.

9. Rouxel T, Grandaubert J, Hane JK, Hoede C, van de Wouw AP, Couloux A Dominguez V, Anthouard V, Bally P, Bourras S, Cozijnsen AJ, Ciuffetti LM, Degrave A, Dilmaghani A, Duret L, Fudal I, Goodwin SB, Gout L, Glaser N, Linglin J, Kema GH, Lapalu N, Lawrence CB, May K, Meyer M, Ollivier B, Poulain J, Schoch CL, Simon A, Spatafora JW, et al: Effector diversification within compartments of the Leptosphaeria maculans genome affected by Repeat-Induced Point Mutations. Nat Commun 2011, 2:202.

10. Eyre-Walker A, Hurst LD: The evolution of isochores. Nat Rev Genet 2011 2:549-555.

11. Galagan JE, Selker EU: RIP: the evolutionary cost of genome defense. Trends Genet 2004, 20:417-423.

12. Gout L, Fudal I, Kuhn ML, Blaise F, Eckert M, Cattolico L, Balesdent MH, Rouxel T: Lost in the middle of nowhere: the AvrLm1 avirulence gene of the Dothideomycete Leptosphaeria maculans. Mol Microbiol 2006, 60:97-80.
13. Fudal I, Ross S, Gout L, Blaise F, Kuhn ML, Eckert MR, Cattolico L, Bernard-Samain S, Balesdent MH, Rouxel T: Heterochromatin-like regions as ecological niches for avirulence genes in the Leptosphaeria maculans genome: map-based cloning of AvrLm6. Mol Plant-Microbe Interact 2007, 20:459-470.

14. Parlange F, Daverdin G, Fudal I, Kuhn ML, Balesdent MH, Blaise F, Grezes-Besset B, Rouxel T: Leptosphaeria maculans avirulence gene AvrLm4-7 confers a dual recognition specificity by the $R / m 4$ and $R / m 7$ resistance genes of oilseed rape, and circumvents RIm4-mediated recognition through a single amino acid change. Mol Microbiol 2009, 71:851-863.

15. Balesdent MH, Fudal I, Ollivier B, Bally P, Grandaubert J, Eber F, Chèvre AM, Leflon M, Rouxel T: The dispensable chromosome of Leptosphaeria maculans shelters an effector gene conferring avirulence towards Brassica rapa. New Phytol 2013, 198:887-898.

16. Fudal I, Ross S, Brun H, Besnard AL, Ermel M, Kuhn ML, Balesdent MH, Rouxel T: Repeat-induced point mutation (RIP) as an alternative mechanism of evolution toward virulence in Leptosphaeria maculans. Mol Plant Microbe Interact 2009, 22:932-941.

17. Van de Wouw AP, Cozijnsen AJ, Hane JK, Brunner PC, McDonald BA, Oliver RP, Howlett BJ: Evolution of linked avirulence effectors in Leptosphaeria maculans is affected by genomic environment and exposure to resistance genes in host plants. PLoS Pathog 2010, 6:e1001180.

18. Daverdin G, Rouxel T, Gout L, Aubertot JN, Fudal I, Meyer M, Parlange F, Carpezat J, Balesdent MH: Genome structure and reproductive behaviour influence the evolutionary potential of a fungal phytopathogen. PLOS Pathog 2012, 8:e1003020.

19. Gout L, Kuhn ML, Vincenot L, Bernard-Samain S, Cattolico L, Barbetti M, Moreno-Rico O, Balesdent MH, Rouxel T: Genome structure impacts molecular evolution at the AvrLm1 avirulence locus of the plant pathogen Leptosphaeria maculans. Environ Microbiol 2007, 9:2978-2992

20. Patron NJ, Waller RF, Cozijnsen AJ, Straney DC, Gardiner DM, Nierman WC Howlett BJ: Origin and distribution of epipolythiodioxopiperazine (ETP) gene clusters in filamentous ascomycetes. BMC Evol Biol 2007, 7:e174.

21. Mendes-Pereira E, Balesdent MH, Brun H, Rouxel T: Molecular phylogeny of the Leptosphaeria maculans-L. biglobosa species complex. Mycol Res 2003, 107:1287-1304.

22. Voigt K, Cozijnsen AJ, Kroymann J, Pöggeler S, Howlett BJ: Phylogenetic relationships between members of the crucifer pathogenic Leptosphaeria maculans species complex as shown by mating type (MAT1-2), actin, and $\beta$-tubulin sequences. Mol Phylogenet Evol 2005, 37:541-557.

23. Fitt BDL, Brun H, Barbetti MJ, Rimmer SR: Worldwide importance of phoma stem canker (Leptosphaeria maculans and L. biglobosa) on oilseed rape (Brassica napus). Eur J Plant Pathol 2006, 114:3-15.

24. West JS, Balesdent MH, Rouxel T, Narcy JP, Huang YJ, Roux J, Steed JM, Fitt $\mathrm{BDL}$, Schmit J: Colonization of winter oilseed rape tissues by $\mathrm{A} / \mathrm{Tox}+$ and $\mathrm{B} /$ Tox0 Leptosphaeria maculans (phoma stem canker) in France and England. Plant Pathol 2002, 51:311-321.

25. Schoch CL, Sung GH, López-Giráldez F, Townsend JP, Miadlikowska J, Hofstetter V, Robbertse B, Matheny PB, Kauff F, Wang Z, Gueidan C, Andrie RM, Trippe K, Ciufetti LM, Wynns A, Fraker E, Hodkinson BP, Bonito G, Groenewald JZ, Arzanlou M, de Hoog GS, Crous PW, Hewitt D, Pfister DH, Peterson K, Gryzenhout M, Wingfield MJ, Aptroot A, Suh SO, Blackwell M, et al: The Ascomycota tree of life: a phylum-wide phylogeny clarifies the origin and evolution of fundamental reproductive and ecological traits. Syst Biol 2009, 58:224-239.

26. Ohm RA, Feau N, Henrissat B, Schoch CL, Horwitz BA, Barry KW, Condon B Copeland AC, Dhillon B, Glaser F, Hesse CN, Kosti I, LaButti K, Lindquist EA, Lucas S, Salamov AA, Bradshaw RE, Ciuffetti L, Hamelin RC, Kema GH, Lawrence C, Scott JA, Spatafora JW, Turgeon BG, de Wit PJ, Zhong S, Goodwin SB, Grigoriev IV: Diverse lifestyles and strategies of plant pathogenesis encoded in the genomes of eighteen Dothideomycetes fungi. PLoS Pathog 2012, 8:e1003037.

27. Schoch CL, Crous PW, Groenewald JZ, Boehm EW, Burgess TI, de Gruyter J, de Hoog GS, Dixon LJ, Grube M, Gueidan C, Harada Y, Hatakeyama S, Hirayama K, Hosoya T, Huhndorf SM, Hyde KD, Jones EBG, Kohlmeyer J, Kruys A, Li YM, Lücking R, Lumbsch HT, Marvanová L, Mbatchou JS, McVay AH, Miller AN, Mugambi GK, Muggia L, Nelsen MP, Nelson P, et al: A class-wide phylogenetic assessment of Dothideomycetes. Stud Mycol 2009, 64:1-15S10

28. Cunningham GH: Dry-rot of Swedes and turnips: its cause and control. N-Z Dep Agric Bull 1927, 133:51 pp. 
29. Pound GS: Variability in Phoma lingam. J Agric Res 1947, 75:113-133.

30. Shoemaker RA, Brun $\mathrm{H}$ : The telemorph of the weakly aggressive segregate of Leptosphaeria maculans. Can J Bot 2001, 79:412-419.

31. de Wit PJ, van der Burgt A, Ökmen B, Stergiopoulos I, Abd-Elsalam KA, Aerts $A L$, Bahkali AH, Beenen HG, Chettri P, Cox MP, Datema E, de Vries RP, Dhillon B, Ganley AR, Griffiths SA, Guo Y, Hamelin RC, Henrissat B, Kabir MS, Jashni MK, Kema G, Klaubauf S, Lapidus A, Levasseur A, Lindquist E, Mehrabi R, Ohm RA, Owen TJ, Salamov A, Schwelm A, et al: The genomes of the fungal plant pathogens Cladosporium fulvum and Dothistroma septosporum reveal adaptation to different hosts and lifestyles but also signatures of common ancestry. PLoS Genet 2012, 8:e1003088.

32. Manning VA, Pandelova I, Dhillon B, Wilhelm LJ, Goodwin SB, Berlin AM, Figueroa M, Freitag M, Hane JK, Henrissat B, Holman WH, Kodira CD, Martin J, Oliver RP, Robbertse B, Schackwitz W, Schwartz DC, Spatafora JW, Turgeon BG, Yandava C, Young S, Zhou S, Zeng Q, Grigoriev IV, Ma LJ, Ciuffetti LM: Comparative genomics of a plant-pathogenic fungus, Pyrenophora tritici-repentis, reveals transduplication and the impact of repeat elements on pathogenicity and population divergence. G3 2013, 3:41-63.

33. Spanu PD, Abbott JC, Amselem J, Burgis TA, Soanes DM, Stüber K, Ver Loren Van Themaat E, Brown JK, Butcher SA, Gurr SJ, Lebrun MH, Ridout CJ, Schulze-Lefert P, Talbot NJ, Ahmadinejad N, Ametz C, Barton GR, Benjdia M, Bidzinski P, Bindschedler LV, Both M, Brewer MT, Cadle-Davidson L, Cadle-Davidson MM, Collemare J, Cramer R, Frenkel O, Godfrey D, Harriman J, Hoede C, et al: Genome expansion and gene loss in powdery mildew fungi reveal tradeoffs in extreme parasitism. Science 2010, 330:1543-1546.

34. Duplessis S, Cuomo CA, Lin YC, Aerts A, Tisserant E, Veneault-Fourrey C, Joly DL, Hacquard S, Amselem J, Cantarel BL, Chiu R, Coutinho PM, Feau N, Field M, Frey P, Gelhaye E, Goldberg J, Grabherr MG, Kodira CD, Kohler A, Kües U, Lindquist EA, Lucas SM, Mago R, Mauceli E, Morin E, Murat C, Pangilinan JL, Park R, Pearson $M$, et al: Obligate biotrophy features unraveled by the genomic analysis of rust fungi. Proc Natl Acad Sci U S A 2011, 108:9166-9171.

35. Kurtz S, Phillippy A, Delcher AL, Smoot M, Shumway M, Antonescu C, Salzberg SL: Versatile and open software for comparing large genomes. Genome Biol 2004, 5:R12.

36. Hane JK, Oliver RP: In silico reversal of repeat-induced point mutation (RIP) identifies the origins of repeat families and uncovers obscured duplicated genes. BMC Genomics 2010, 11:655.

37. Li L, Stoeckert CJ Jr, Roos DS: OrthoMCL: identification of ortholog groups for eukaryotic genomes. Genome Res 2003, 13:2178-2189.

38. Gardiner DM, Cozijnsen AJ, Wilson LM, Pedras MS, Howlett BJ: The sirodesmin biosynthetic gene cluster of the plant pathogenic fungus Leptosphaeria maculans. Mol Microbiol 2004, 53:1307-1318.

39. Khaldi N, Collemare J, Lebrun MH, Wolfe KH: Evidence for horizontal transfer of a secondary metabolite gene cluster between fungi. Genome Biol 2008, 9:R18.

40. Hawksworth DL: Global species numbers of fungi: are tropical studies and molecular approaches contributing to a more robust estimate? Biodiv Cons 2012, 21:2425-2433.

41. Crous PW, Summerell BA, Carnegie AJ, Wingfield MJ, Hunter GC, Burgess TI, Andjic V, Barber PA, Groenewald JZ: Unravelling Mycosphaerella: do you believe in genera? Persoonia 2009, 23:99-118.

42. Quaedvlieg W, Kema GH, Groenewald JZ, Verkley GJ, Seifbarghi S, Razavi M, Mirzadi Gohari A, Mehrabi R, Crous PW: Zymoseptoria gen. nov.: a new genus to accommodate Septoria-like species occurring on graminicolous hosts. Persoonia 2011, 26:57-69.

43. Sharpton TJ, Stajich JE, Rounsley SD, Gardner MJ, Wortman JR, Jordar VS, Maiti R, Kodira CD, Neafsey DE, Zeng Q, Hung CY, McMahan C, Muszewska A, Grynberg M, Mandel MA, Kellner EM, Barker BM, Galgiani JN, Orbach MJ, Kirkland TN, Cole GT, Henn MR, Birren BW, Taylor JW: Comparative genomic analyses of the human fungal pathogens Coccidioides and their relatives. Genome Res 2009, 19:1722-1731.

44. Condon BJ, Leng Y, Wu D, Bushley KE, Ohm RA, Otillar R, Martin J, Schackwitz W, Grimwood J, MohdZainudin N, Xue C, Wang R, Manning VA Dhillon B, Tu ZJ, Steffenson BJ, Salamov A, Sun H, Lowry S, LaButti K, Han J, Copeland A, Lindquist E, Barry K, Schmutz J, Baker SE, Ciuffetti LM, Grigoriev $\mathrm{IV}$, Zhong S, Turgeon BG: Comparative genome structure, secondary metabolite, and effector coding capacity across Cochliobolus pathogens. PLOS Genet 2013, 9:e1003233.
45. Hane JK, Rouxel T, Howlett BJ, Kema GH, Goodwin SB, Oliver RP: A novel mode of chromosomal evolution peculiar to filamentous Ascomycete fungi. Genome Biol 2011, 12:R45.

46. Wicker T, Oberhaensli S, Parlange F, Buchmann JP, Shatalina M, Roffler S, Ben-David R, Doležel J, Šimková H, Schulze-Lefert P, Spanu PD, Bruggmann R, Amselem J, Quesneville H, Ver Loren Van Themaat E, Paape T, Shimizu KK, Keller B: The wheat powdery mildew genome shows the unique evolution of an obligate biotroph. Nat Genet 2013, 45:1092-1096.

47. Idnurm A, Howlett BJ: Analysis of loss of pathogenicity mutants reveals that repeat-induced point mutations can occur in the Dothideomycete Leptosphaeria maculans. Fungal Genet Biol 2003, 39:31-37.

48. Clutterbuck AJ: Genomic evidence of repeat-induced point mutation (RIP) in filamentous ascomycetes. Fungal Genet Biol 2011, 48:306-326.

49. Goyon C, Barry C, Grégoire A, Faugeron G, Rossignol JL: Methylation of DNA repeats of decreasing sizes in Ascobolus immersus. Mol Cell Biol 1996, 16:3054-3065

50. Irelan JT, Selker EU: Gene silencing in filamentous fungi: RIP, MIP and quelling. J Genet 1996, 75:313-324

51. Rebollo R, Horard B, Hubert B, Vieira C: Jumping genes and epigenetics: Towards new species. Gene 2010, 454:1-7.

52. Dilmaghani A, Gladieux P, Gout L, Giraud T, Brunner PC, Stachowiak A Balesdent $\mathrm{MH}$, Rouxel T: Migration patterns and changes in population biology associated with the worldwide spread of the oilseed rape pathogen Leptosphaeria maculans. Mol Ecol 2012, 21:2519-2533.

53. Dilmaghani A, Gout L, Moreno-Rico O, Dias JS, Coudard L, Balesdent MH, Rouxel T: Clonal populations of Leptosphaeria maculans contaminating cabbage in Mexico. Plant Pathology 2013, 62:520-532.

54. Silva JC, Loreto EL, Clark JB: Factors that affect the horizontal transfer of transposable elements. Curr Issues Mol Biol 2004, 6:57-71.

55. Walsh AM, Kortschak RD, Gardner MG, Bertozzia T, Adelsona DL: Widespread horizontal transfer of retrotransposons. Proc Natl Acad Sci U S A 2013, 15:1012-1016.

56. Loreto EL, Carareto CM, Capy P: Revisiting horizontal transfer of transposable elements in Drosophila. Heredity 2008, 100:545-554.

57. Daboussi MJ, Capy P: Transposable elements in filamentous fungi. Annu Rev Microbiol 2003, 57:275-299.

58. Delprat A, Negre B, Puig M, Ruiz A: The transposon Galileo generates natural chromosomal inversions in Drososphila by ectopic recombination. PLoS One 2009, 4:e7883.

59. Zhao H, Bourque $\mathrm{G}$ : Recovering genome rearrangements in the mammalian phylogeny. Genome Res 2009, 19:934-942.

60. Friesen TL, Stukenbrock EH, Liu Z, Meinhardt S, Ling H, Faris JD, Rasmussen JB, Solomon PS, McDonald BA, Oliver RP: Emergence of a new disease as a result of interspecific virulence gene transfer. Nat Genet 2006, 38:953-956.

61. Pedras MSC, Taylor JL, Nakashima TT: A novel chemical signal from the "blackleg" fungus: beyond phytotoxins and phytoalexins. J Org Chem 1993, 58:4778-4780.

62. Chuma I, Isobe C, Hotta Y, Ibaragi K, Futamata N, Kusaba M, Yoshida K, Terauchi R, Fujita Y, Nakayashiki H, Valent B, Tosa Y: Multiple translocation of the AVR-Pita effector gene among chromosomes of the rice blast fungus Magnaporthe oryzae and related species. PLOS Pathog 2011, 7:e1002147.

63. Petrie GA: Variability in Leptosphaeria maculans (Desm.) Ces. et De Not., the cause of blackleg of rape. In PhD thesis. Saskatoon, Canada: University of Saskatchewan; 1969:215 pp.

64. Rouxel T, Balesdent MH: The stem canker (blackleg) fungus, Leptosphaeria maculans, enters the genomic era. Mol Plant Pathol 2005, 6:225-241.

65. Fitt BDL, Huang YJ, van den Bosch F, West JS: Coexistence of related pathogen species on arable crops in space and time. Annu Rev Phytopathol 2006, 44:163-182.

66. Belstein MA, Nagalingum NS, Clements MD, Manchester SR, Matthews S: Dated molecular phylogenies indicate a Miocene origin for Arabidopsis thaliana. Proc Natl Acad Sci U S A 2010, 107:18724-18728.

67. Kang S, Sweigard JA, Valent B: The PWL host specificity gene family in the blast fungus Magnaporthe grisea. Mol Plant Microbe Interact 1995 8:939-948.

68. Couch BC, Fudal I, Lebrun MH, Tharreau D, Valent B, van Kim P, Nottéghem $J$, Kohn LM: Origins of host-specific populations of the blast pathogen Magnaporthe oryzae in crop domestication with subsequent expansion of pandemic clones on rice and weeds of rice. Genetics 2005, 170:613-630. 
69. West JS, Kharbanda PD, Barbetti MJ, Fitt BDL: Epidemiology and management of Leptosphaeria maculans (phoma stem canker) on oilseed rape in Australia, Canada and Europe. Plant Pathology 2001, 50:10-27.

70. Van de Wouw AP, Thomas VL, Cozijnsen AJ, Marcroft SJ, Salisbury PA, Howlett BJ: Identification of Leptosphaeria biglobosa 'canadensis' on Brassica juncea stubble from northern New South Wales, Australia. Australas Plant Dis Notes 2008, 3:124-128.

71. Vincenot L, Balesdent MH, Li H, Barbetti MJ, Sivasithamparam K, Gout L, Rouxel T: Occurrence of a new subclade of Leptosphaeria biglobosa in Western Australia. Phytopathology 2008, 98:321-329.

72. Soyer JL, El Ghalid M, Glaser N, Ollivier B, Linglin J, Grandaubert J, Balesdent $\mathrm{MH}$, Connolly LR, Freitag M, Rouxel T, Fudal I: Epigenetic control of effector gene expression in the plant pathogenic fungus Leptosphaeria maculans. PLOS Genet 2014, 10:e1004227.

73. Wang Q, Han C, Ferreira AO, Yu X, Ye W, Tripathy S, Kale SD, Gu B, Sheng Y, Sui $Y$, Wang $X$, Zhang Z, Cheng B, Dong S, Shan W, Zheng X, Dou D, Tyler BM, Wang Y: Transcriptional programming and functional interactions within the Phytophthora sojae RXLR effector repertoire. Plant Cell 2011, 23:2064-2086

74. Zerbino DR, Birney E: Velvet: algorithms for de novo short read assembly using de Bruijn graphs. Genome Res 2008, 18:821-829.

75. Salamov AA, Solovyev W: Ab initio gene finding in Drosophila genomic DNA. Genome Res 2000, 10:516-522.

76. Lomsadze A, Ter-Hovhannisyan V, Chernoff Y, Borodovsky M: Gene identification in novel eukaryotic genomes by self-training algorithm. Nucleic Acids Res 2005, 33:6494-6506.

77. Foissac S, Gouzy J, Rombauts S, Mathe C, Amselem J, Sterck L, de Peer YV, Rouze P, Schiex T: Genome Annotation in Plants and Fungi: EuGene as a model platform. Current Bioinformatics 2008, 3:87-97.

78. Smit AFA, Hubley R, Green P: RepeatMasker Open-3.0. [www.repeatmasker.org]

79. Berriman M, Rutherford K: Viewing and annotating sequence data with Artemis. Brief Bioinform 2003, 4:124-132

80. Altschul SF, Gish W, Miller W, Myers EW, Lipman DJ: Basic local alignment search tool. $J$ Mol Biol 1990, 215:403-410.

81. Quevillon E, Silventoinen V, Pillai S, Harte N, Mulder N, Apweiler R, Lopez R: InterProScan: protein domains identifier. Nucleic Acids Res 2005, 33:W116-W120

82. Hunter S, Jones P, Mitchell A, Apweiler R, Attwood TK, Bateman A, Bernard T, Binns D, Bork P, Burge $S$, de Castro E, Coggill P, Corbett M, Das U, Daugherty L, Duquenne L, Finn RD, Fraser M, Gough J, Haft D, Hulo N, Kahn D, Kelly E, Letunic I, Lonsdale D, Lopez R, Madera M, Maslen J, McAnulla C, McDowall J, et al: InterPro in 2011: new developments in the family and domain prediction database. Nucleic Acids Res 2012, 40:D306-D312.

83. Bendtsen JD, Nielsen H, von Heijne G, Brunak S: Improved prediction of signal peptides: SignalP 3.0. J Mol Biol 2004, 340:783-795.

84. Emanuelsson O, Nielsen H, Brunak S, von Heijne G: Predicting subcellular localization of proteins based on their $\mathrm{N}$-terminal amino acid sequence. J Mol Biol 2000, 300:1005-1016.

85. Krogh A, Larsson B, von Heijne G, Sonnhammer ELL: Predicting transmembrane protein topology with a hidden markov model: application to complete genomes. J Mol Biol 2001, 305:567-580.

86. Flutre T, Duprat E, Feuillet C, Quesneville H: Considering transposable element diversification in de novo annotation approaches. Plos One 2011, 6:e16526.

87. Jurka J, Kapitonov W, Pavlicek A, Klonowski P, Kohany O, Walichiewicz J: Repbase Update, a database of eukaryotic repetitive elements. Cytogenet Genome Res 2005, 110:462-467.

88. Wicker T, Sabot F, Hua-Van A, Bennetzen JL, Capy P, Chalhoub B, Flavell A, Leroy P, Morgante M, Panaud O, Paux E, SanMiguel P, Schulman AH: A unified classification system for eukaryotic transposable elements. Nat Rev Genet 2007, 8:973-982.

89. Kapitonov W, Jurka J: A universal classification of eukaryotic transposable elements implemented in Repbase. Nat Rev Genet 2008, 9:411-412.

90. Larkin MA, Blackshields G, Brown NP, Chenna R, McGettigan PA, McWilliam $H$, Valentin F, Wallace IM, Wilm A, Lopez R, Thompson JD, Gibson TJ, Higgins DG: Clustal W and Clustal X version 2.0. Bioinformatics 2007, 23:2947-2948

91. Rice P, Longden I, Bleasby A: EMBOSS: The European Molecular Biology Open Software Suite. Trends Genet 2000, 16:276-277.
92. Marchler-Bauer A, Anderson JB, Chitsaz F, Derbyshire MK, DeWeese-Scott C, Fong JH, Geer LY, Geer RC, Gonzales NR, Gwadz M, He S, Hurwitz DI, Jackson JD, Ke Z, Lanczycki CJ, Liebert CA, Liu C, Lu F, Lu S, Marchler GH, Mullokandov M, Song JS, Tasneem A, Thanki N, Yamashita RA, Zhang D, Zhang N, Bryant SH: CDD: a Conserved Domain Database for the functional annotation of proteins. Nucleic Acids Res 2009, 39:D225-D229.

93. Hane JK, Oliver RP: RIPCAL: a tool for alignment-based analysis of repeat-induced point mutations in fungal genomic sequences. BMC Bioinformatics 2008, 9:478.

94. McKay SJ, Vergara IA, Stajich J: Using the Generic Synteny Browser (Gbrowse_syn). Curr Protoc Bioinfo 2010, 9. Unit 9.12

95. Dewey CN: Aligning multiple whole genomes with Mercator and MAVID. Methods Mol Bio 2007, 395:221-236.

96. Price MN, Dehal PS, Arkin AP: FastTree 2-approximately maximum-likelihood trees for large alignments. PLoS One 2010, 5:e9490.

97. Talavera G, Castresana J: Improvement of phylogenies after removing divergent and ambiguously aligned blocks from protein sequence alignments. Syst Biol 2007, 56:564-577.

98. Drummond AJ, Suchard MA, Xie D, Rambaut A: Bayesian phylogenetics with BEAUti and the BEAST 1.7. Mol Biol Evol 2012, 29:1969-1973.

99. Sanderson MJ: r8s: inferring absolute rates of molecular evolution and divergence times in the absence of a molecular clock. Bioinformatics 2003, 19:301-302.

100. Floudas D, Binder M, Riley R, Barry K, Blanchette RA, Henrissat B, Martínez AT, Otillar R, Spatafora JW, Yadav JS, Aerts A, Benoit I, Boyd A, Carlson A, Copeland A, Coutinho PM, de Vries RP, Ferreira P, Findley K, Foster B, Gaskell J, Glotzer D, Górecki P, Heitman J, Hesse C, Hori C, Igarashi K, Jurgens JA, Kallen N, Kersten $\mathrm{P}$, et al: The Paleozoic origin of enzymatic lignin decomposition reconstructed from 31 fungal genomes. Science 2012, 336:1715-1719.

101. Gueidan C, Ruibal C, de Hoog GS, Schneider H: Rock-inhabiting fungi originated during periods of dry climate in the late Devonian and middle Triassic. Fungal Biol 2011, 115:987-996.

102. Miller MA, Pfeiffer W, Schwartz T: Creating the CIPRES science gateway for inference of large phylogenetic trees. In Proceedings of the Gateway Computing Environments Workshop (GCE). New Orleans, LA: Addede; 2010:1-8.

103. Bolstad BM, Irizarry RA, Astrand M, Speed TP: A comparison of normalization methods for high density oligonucleotide array data based on variance and bias. Bioinformatics 2003, 19:185-193.

104. Irizarry RA, Hobbs B, Collin F, Beazer-Barclay YD, Antonellis KJ, Scherf U, Speed TP: Exploration, normalization, and summaries of high density oligonucleotide array probe level data. Biostatistics 2003, 4:249-264.

105. Simon A, Biot E: ANAIS: analysis of NimbleGen arrays interface. Bioinformatics 2010, 26:2468-2469.

106. Van de Wouw AP, Marcroft SJ, Barbetti MJ, Hua L, Salisbury PA, Gout L, Rouxel T, Howlett BJ, Balesdent MH: Dual control of avirulence in Leptosphaeria maculans towards a Brassica napus cultivar with sylvestris-derived resistance suggests involvement of two resistance genes. Plant Pathology 2009, 58:305-313.

107. Trapnell C, Pachter L, Salzberg SL: TopHat: discovering splice junctions with RNA-Seq. Bioinformatics 2009, 25:1105-1111.

108. Trapnell C, Williams BA, Pertea G, Mortazavi A, Kwan G, van Baren MJ, Salzberg SL, Wold BJ, Pachter L: Transcript assembly and quantification by RNA-Seq reveals unannotated transcripts and isoform switching during cell differentiation. Nat Biotech 2010, 28:511-515.

\section{doi:10.1186/1471-2164-15-891}

Cite this article as: Grandaubert et al:: Transposable element-assisted evolution and adaptation to host plant within the Leptosphaeria maculans-Leptosphaeria biglobosa species complex of fungal pathogens. BMC Genomics 2014 15:891. 